\title{
Spectrum of gas migration phenomena across multi-layered sealing sequences
}

C. Bertoni ${ }^{1}$, J. Cartwright ${ }^{1}$, M. Foschi ${ }^{1}$, J. Martin ${ }^{2}$

1-Department of Earth Sciences, University of Oxford, South Parks Rd, Oxford OX1

3AN

2-Shell Exploration, Menara Shell, Jalan Tun Sambanthan 211, Kuala Lumpur, 50470, Malaysia.

\section{Acknowledgements}

The PEP50119 Joint Venture Partners (Shell, OMV, PTTEP and Mitsui E\&P Australia) are acknowledged for providing the Sirius-Rigel 3D survey for this study, and for the permission to publish the results. We are very grateful to the Shell New Zealand team in Kuala Lumpur, for giving fundamental technical input the project, and to Jos Lutz for his help with the data. This research has highly benefited from discussions with Bruce Levell, Pieter Van Rensbergen, Dirk Smith, Ilya Ostanin, Floris Strijbos, Craig Shipp, Erdem Idiz, Ian Clark and John Stainforth. The Waka 3D survey, the 2D data and the well data are courtesy of New Zealand Petroleum and Minerals. We are also thankful to Schlumberger for the use of the Petrel software and to Halliburton for ProMAXSeiSpace processing software. Dave Samson helped with graphics. Our thanks go to Reynaldo Cardona and an anonymous reviewer whose comments significantly helped improve the manuscript. 


\section{ABSTRACT}

We describe a spectrum of seismic high-amplitude anomalies from the Great South and Canterbury Basins (offshore New Zealand) that have a number of characteristics that make them distinct from previously described hydrocarbon-related amplitude anomalies. We propose a new classification scheme that is based on the specific vertical stacking of the anomalies, and thereby reflects their genetic inter-relationships.

We demonstrate by combining AVO (Amplitude Versus Offset) and other attribute analyses that the anomalies are the product of gas migration across thick sequences of low permeability sediments and identify specific units where migration is focused through discontinuities (e.g. faults), and storage units where the gas spreads laterally. Based on our observations we argue that fluid flow phenomena in which Darcy flow must have occurred can be hosted within low permeability layers that would normally be regarded as high quality sealing sequences.

The documentation of a wide range of gas-related anomalies developed in a relatively uniform lithostratigraphy and in similar basinal contexts allows us to infer a migration sequence based on the morpho-structural and geophysical characteristics of the anomalies. We suggest that the shape of the composite anomalies is directly controlled by gas flux and by probably quite subtle variations in physical properties of the host sediments. The distribution of the anomalies is generally correlated with maximum burial regions of the most prospective source rock intervals that are currently in the gas maturation window. This spatial coincidence strongly suggests that the 
anomalies result from vertical migration of thermogenic gas from these underlying source kitchens.

\section{INTRODUCTION}

Hydrocarbon migration is traditionally believed to occur mostly through high permeability (few $\mathrm{mD}$ and higher) sediments and fractures or faults, while low permeability ( $\mathrm{nD}$ to $\mu \mathrm{D}$ ) deposits such as seals or aquicludes prevent this process favouring the formation of economic accumulations (Bear, 1972; Downey, 1984; England et al., 1987; Roberts and Cordell, 1980; Todd, 1980). The transition between these two key elements of the petroleum system takes place in a range of permeability where sediments can act either as reservoirs or low quality seals.

In early offshore hazard assessments for the prevention of blowouts and for production platform safety in the Gulf of Mexico and in the North Sea, various types of gas migration features were recognised and described from seismic data (Brooks et al., 1986; Hovland, 1983; Hovland and Judd, 1988; Roberts et al., 1990; Roberts et al., 1992; Roberts and Cordell, 1980). These studies initiated a broader discussion of seal efficiency by demonstrating that gas was commonly able to cross thick layers of low permeability sediments (Hovland and Sommerville, 1985).

More recently, a number of studies have highlighted that hydrocarbons can migrate vertically across even deeply buried low permeability deposits by exploiting seal bypass systems such as faults, pipes and intrusions (Andresen and Huuse, 2011; Bertoni and Cartwright, 2015; Cartwright et al., 2007; Moss et al., 2012; Ostanin et al., 2013). Evidence of vertical and focused fluid flow through sealing sequences using 
these cross-stratal pathways has accumulated in the past decade largely through the greater resolution and imaging quality of modern 3D seismic surveys (Berndt, 2005; Cartwright et al., 2007; Ho et al., 2012; Hustoft et al., 2009; Mazzini et al., 2003; Van Rensbergen et al., 2003). Seismic data can be interpreted to reconstruct timing and pathways of migrating fluid in a basin (Andresen, 2012; Ho et al., 2012). However, the onset, duration and fluxes of the leakage elements in these particular systems remain poorly constrained.

In this study we focus on the 3D seismic expression of vertical gas migration. We present seismic examples of a range of gas migration phenomena from the Great South Basin (GSB) and Canterbury Basin (CB), offshore New Zealand (Figure 1). These basins are represented by largely fine-grained, slope sedimentary sequences deposited during the passive margin stage of basin development, in the Late Cretaceous and Cenozoic (Constable et al., 2013). The extensive seismic data coverage (2D and 3D) and high quality imaging allows a thorough subsurface mapping of this basin. The interpretation of these data reveals a broad spectrum of fluid migration-related features (direct hydrocarbon indicators, DHIs) and seal bypass systems including pipes, hydrothermal vents, igneous intrusions, and both tectonic and polygonal fault arrays. The DHIs are mainly developed in the form of simple to complex, vertically stacked amplitude anomalies (AAs), which are hosted within a fine-grained dominated sequence of Late Cretaceous to Oligocene age, exhibit a wide spectrum of geometries, and extend for up to $1000 \mathrm{~m}$ (over $3000 \mathrm{ft}$ ) vertically, suggesting a considerable role for vertical fluid migration through what would normally be considered classically sealing sequences. 
Most of the AAs are complex assemblages of individual amplified seismic reflections, but with some novel characteristics that do not appear to have been reported previously. It is challenging to classify them using the standard nomenclature. Hence, we briefly review the current nomenclature of seismic anomalies and propose new terminology where needed.

The aims of this paper are: 1) to understand the nature of the AAs observed in the study area, 2) to analyse what controls the spectrum of geometries observed, their lateral vs. vertical extent and interconnection, and 3) apply the new findings to better constrain vertical gas migration mechanisms in other basins worldwide. We combine mapping and qualitative interpretation techniques with post-stack attribute analysis (amplitude, frequency, discontinuity) and quantitative pre-stack analysis (AVO, i.e. Amplitude Versus Offset). Seismic stratigraphic interpretation and long distance wellties are used to calibrate the sediment hosting the anomalies and place them in a basinal context. The paper concludes with an evolutionary model that links all the observations into a broader framework of dominantly vertical gas migration across a thick, fine-grained basin fill succession. This model should be applicable to many other basins, where the low incidence of major carrier beds means that most hydrocarbon migration is sub-vertical to vertical.

\section{TERMINOLOGY}

Seismic amplitude anomalies can be associated with gaseous fluids in sediments (Hovland, 1983; Judd and Hovland, 2007; Løseth et al., 2009; Sheriff, 1975). A significant application of the study of AAs is the detection of the presence of DHIs and 
migration pathways (Chadwick et al., 2004; Chadwick et al., 2014; Hovland, 1983; Hovland and Judd, 1988; Judd and Hovland, 2007). In this context, the classic nomenclature for gas-related seismic anomalies is focused on single or shallow gas charged layers and includes bright spots (high amplitude anomalies), dim spots, blanking or acoustic wipe-out zones (low amplitude anomalies), flat spots, phase reversals and amplitude versus offset (AVO) analysis (Judd and Hovland, 2007; Løseth et al., 2009; Roberts et al., 1999; Sheriff, 1975). A comprehensive review of the different types of anomalies has been undertaken by Judd and Hovland (2007).

The increased quality of 3D seismic data has allowed more detailed analysis of these gas-related amplitude anomalies in more recent years (Calvès et al., 2008; Ostanin et al., 2013; Serié et al., 2017). Renewed attention has been focused on how these DHls connect in three dimensions with other fluid flow evidence and seal bypass systems, to form hydrocarbon plumbing systems (Andresen, 2012). However, the prevailing terminology does not yet reflect these observational advances. Composite or stacked AAs are commonly included under the widely encompassing term 'gas chimney', which is associated with extensive vertical disturbance of the seismic response, typically showing low amplitudes (wipe-out) zones, bordered by high amplitude anomalies, due to the presence of stacked gas-charged intervals (Bjørkum et al., 1998; Heggland, 1997, 1998; Hovland and Judd, 1988; Meldahl et al., 2001). Seismic gas chimneys can also be associated with features related to seepage, like pockmarks, mud volcanoes, and carbonate formations (Heggland, 1997, 1998; Heggland et al., 1996). Some of these composite gas-related anomalies have been previously named 'Christmas-tree' anomalies (Ben-Brahim et al., 1999). 
A specific class of what could be regarded as 'composite' AAs are gas fronts. These are generally considered to be the seismic expression of laterally extensive free gas migration through the sediments (or gas 'blankets' as defined in Hovland, 1983). Gas fronts are generally continuous and often exhibit irregular high amplitude seismic reflections, or stacked fringes of amplified reflections. These gas front anomalies are particularly evident when they cross-cut the primary stratigraphic horizons, extending laterally for $10 \mathrm{~s} \mathrm{~km} \mathrm{(mi).} \mathrm{Gas} \mathrm{fronts} \mathrm{have} \mathrm{only} \mathrm{thus} \mathrm{far} \mathrm{been} \mathrm{described} \mathrm{from} \mathrm{shallow}$ depths in basins for example at the free gas interface of the sulphate-methane transition zone (Moss et al., 2012; Schattner et al., 2012; Sela-Adler et al., 2015), or at the base of the gas hydrate stability zone (Milkov et al., 2005; Naudts et al., 2010; Otsuka et al., 2011; Rao et al., 2001).

The continuous improvements in resolution of seismic data, and new targeted seismic processing techniques, have begun to highlight the internal complexity of composite AAs. Understanding the internal character of the AAs is particularly important as it can help understand the specific gas migration mechanism involved in their formation. As a consequence, there is a need to adapt and expand the original terminology to include the suite of stacked and composite anomalies. Recently, the new term 'Vertical Anomaly Clusters' (VACs) was introduced by Foschi et al. (2014) to describe the vertical stacking of high-amplitude anomalies ('bright spots'), in gas charged thin multi-layers within hemipelagite sealing sequences in the Falkland Platform. This term was introduced specifically to convey the notion that the many individual amplitude anomalies of each successive layer were linked vertically by the migration process i.e. they were a genetically related assemblage or 'composite' AAs. 


\section{DATASET AND METHODOLOGY}

The dataset used in this study consists of seismic (2D and 3D) and well data located in the Great South and Canterbury basins, offshore the New Zealand South Island (Figure 1). Two 3D surveys (Sirius-Rigel 3D and Waka 3D) and a grid of regional 2D lines have been selected for this study. The Sirius-Rigel 3D survey is located in the GSB, where it covers an area of approximately $4800 \mathrm{sq} \mathrm{km} \mathrm{(over} 1800 \mathrm{sq} \mathrm{mi}$ ). It was acquired by Polarcus for the previous licence block operator, OMV, and its Joint Venture partners, with the support of the current block operator (Shell), in late 2011- early 2012. The data were acquired with eight $6 \mathrm{~km}$-long streamers, bin spacing of $6.25 \times 37.5 \mathrm{~m}(20.5 \times 123 \mathrm{ft})$, record length of $9.2 \mathrm{~s}$ and sample interval of $2 \mathrm{~ms}$ (and resampled to $4 \mathrm{~ms}$ in the final processed data). The data was processed for optimal zero phase. The vertical resolution is approximately $10 \mathrm{~m}$ (ca. $33 \mathrm{ft}$ ) in the first $2-3 \mathrm{~s}$ TWT (the interval of interest of this study), based on the Widess relation (Widess, 1973). This is calculated using an average frequency of $50 \mathrm{~Hz}$ and seismic velocity of $2000 \mathrm{~m} / \mathrm{s}$, which is the value used to perform a first-pass depth conversion of the vertical measurements taken originally in TWT. Common depth point (CDP) gathers on selected sub-volumes were then used for reprocessing, detailed velocity picking and AVO analysis.

The Waka 3D survey in the CB was acquired by PGS for the licence block operators (Anadarko and Joint Venture Partners), with $6 \times 5100 \mathrm{~m}$ (ca. $3.17 \mathrm{mi}$ ) streamers. Data acquisition took place in early 2009, with a record length just over 6s and a sample rate of $2 \mathrm{~ms}$. The survey covers over $1100 \mathrm{sq} . \mathrm{km}$ full fold, and was processed for optimal zero phase. Data polarity for both 3D surveys is Society of Exploration Geophysicists (SEG) positive polarity (American): a positive reflection 
coefficient is represented by a central peak. The convention used in this study for the colour display is that red corresponds to a peak, and blue to a trough (respectively, grey and black in the black and white version of the figures, where the zero crossing is white).

An extensive grid of 2D seismic lines was also available for regional analysis and well correlation, the most relevant and best quality surveys being OMV08-OMV10 and DUN06 (Figure 1), with CB82, CB84, CB98 additionally used for regional interpretation.

Only a small number of exploration wells have been drilled in the past 40 years, almost exclusively in shelfal areas on the western flank of the GSB and CB. These wells provide long-distance ties to the $3 \mathrm{D}$ seismic surveys, through the $2 \mathrm{D}$ seismic lines (Figures $1 \& 2$ ). This allows defining the lithological and stratigraphic context of the sediments hosting the seismic anomalies. The nomenclature of the seismic horizons has been largely based on the sequence stratigraphic framework produced by Constable et al. (2013), with the addition of further horizons where needed. In order to constrain the possible vertical changes of sediment properties within the study interval, we correlated the horizons from the Tara- 1 and Toroa- 1 wells on the shelf to their equivalents in the basin, and we interpreted the lithology of these intervals based on seismic and sequence stratigraphic observations (Constable et al., 2013). This longdistance well tie is then linked to the stratigraphic distribution of the anomalies mapped in the deep GSB.

A number of wells found hydrocarbon (gas and condensate) in Cretaceous reservoirs (Galleon-1, Clipper-1 and Kawau-1). The most recently drilled well is Caravel- 
1 , located within the Waka 3D survey, in the CB. Although the Caravel-1 well results have not been released, some relevant information has been published (Blanke, 2015).

\section{GEOLOGICAL BACKGROUND}

The seismic stratigraphic succession within the study area spans from Jurassic to Recent sediments. A pre-rift sequence of Permian to Cretaceous age represents the basement for the purposes of this study. In the area of interest, regional correlation allows assignment of this basement to the Murihuku, Maita, Caples and Rakaia Terranes mapped onshore and identified in the offshore, based on gravity and magnetic data (Pryer et al., 2013) (Figure 1).

The Murihuku basement terrane includes marine volcanic arc deposits and proximal deltaic sediments and coals, which produce well-layered sequences, imaged on seismic data as packages of high-amplitude reflections, as observed in different New Zealand offshore basins (Bache et al., 2014; Pryer et al., 2013). The Maitai South and Caples South basement terranes include ophiolites, volcaniclastics, and partly metamorphosed marine clastic sediments, and are nearly acoustically transparent on seismic data. The Rakaia terrane is an accreted subduction complex with a depositional age from Permian to Triassic for the sedimentary rocks (Wandres and Bradshaw, 2005). The transition between different acoustic basement facies corresponds to major NW-SE trending crustal discontinuities (Bache et al., 2014; Pryer et al., 2013), which might act as a focus for intense basement deformation, volcanic activity and deep crustal fluid circulation. 
The sedimentary sequence overlying the basement records the final separation of New Zealand from the rest of Gondwana, which occurred in the area from Early to Late Cretaceous (100-85 Ma) (Bache et al., 2014). Widespread intracontinental rifting and extension occurred at this time. The related syn-rift depositional units (seismic horizons Top Basement to K50, Figure 2) are bounded by horsts and arranged into halfgraben wedges. These syn-rift wedges are imaged on seismic data as discontinuous internal high- to mid-amplitude reflections, onlapping the flanks of the horsts (Figure 2).

The syn-rift unit is overlain by a multi-stage Late Cretaceous to Miocene post-rift series (Constable et al., 2013). Within this series, the main focus of this study is the unit bounded at the base by horizon $\mathrm{K} 50$ and at the top by horizon T70, as it hosts most of the seismic anomalies under study (Figure 2). In the distal part of the basin, the seismic facies of the post rift series is characterised by low- to moderate-amplitude, parallel and relatively continuous seismic reflections (Figure 3). This acoustic expression is typical of hemipelagic sediments. On the shelf adjacent to the CB (well Cutter-1), the Eocene is represented by claystones and siltstones with very high siliceous (microcrystalline quartz) content, up to $95 \%$. The most distal well (Caravel-1) drilled through a thick sequence of Paleocene to Eocene fine-grained sediments characterised by relatively high porosities (30-40\%), low permeability $(0.4-1.2 \mathrm{mD})$, and $20-30 \%$ clay and high quartz content (55-70\%), in microcrystalline form (Blanke, 2015). These sediments are the closest analogue to the deep water deposits in the study area.

Above the post-rift series, a Miocene to Recent syn-orogenic unit has also been recognized in the basin. The deposition of this clastic unit is related to the oblique collision at the plate tectonic margin and the formation of the Southern Alps (Constable 
et al., 2013). This tectonic phase has created inversion structures in parts of the GSB and CB. Widespread slope-parallel mounded deposits are also recorded in this unit and reflections show localised convex and concave upwards geometries with internal onlap and downlap. Some of these mounded deposits have been interpreted as the result of slope-parallel processes such as contour currents (contourite mounds in Figure 2) (Lu et al., 2003; Party, 1999).

\section{ANALYSIS OF THE AAs}

A large number of anomalous high amplitude seismic reflections are clearly observed and have been mapped in the post-rift series of the GSB and CB (Figure 3 and 4). The geometry and acoustic character of these amplitude anomalies (AAs) is variable and complex. The AAs are distinguished from the primary depositional sequences by their strong localised amplification, either acoustically positive or negative, of the host stratal reflections (Figure 3). The AAs can be represented either by a single isolated reflection or a series of vertically stacked anomalies, which can be either concordant to or discordant with the host stratal reflections.

Based on these diagnostic characteristics, the AAs were mapped on the $3 \mathrm{D}$ seismic surveys (Sirius-Rigel in the GSB and Waka in the CB). The interpretation was then extended from the better imaging quality and spatial coverage of the $3 \mathrm{D}$ surveys to the 2D dataset (Figure 4). The resulting map shows that the AAs are widespread over a

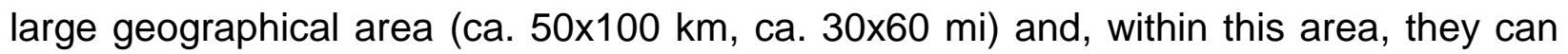
be grouped into clusters (Figure 4). The AAs are mostly of a composite character, and collectively define a spectrum of the different types observed. Therefore, we first 
describe the different types of AAs and summarise their main characteristics with a schematic diagram (Figure 5). Secondly, we describe how they combine to form composite anomalies. Finally, we show how the composite AAs aggregate together to form semi-regional assemblages of composite anomalies.

\section{Simple VACs}

A ubiquitous type of $A A$ in the central part of the GSB is represented by strong, localised and vertically stacked amplifications of the host reflections, which can be acoustically positive or negative (Figure 5 and 6). These AAs are strata bound, i.e. they are concordant with the hosting reflections, exhibit sharp lateral amplitude cut-offs, and do not typically show sign of erosion, or other forms of stratigraphic discordance, and do not conform to structure.

Time-slices and horizon based amplitude maps both show that the morphology of the AAs varies from ribbon-shaped to irregularly elliptical, commonly with a single dominant trend adopted by their long axes, consistent with some form of fault control on

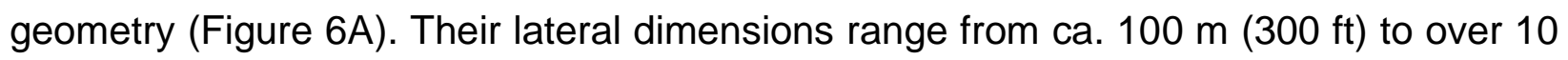
$\mathrm{km}(6 \mathrm{mi})$. On seismic profiles, individual AAs are seen to stack vertically into closely spaced groups that may or may not also be laterally clustered (Figure $6 \mathrm{~B}$ and $\mathrm{C}$ ). A defining characteristic is that these vertically stacked clusters exhibit a significant degree of overlap from one individual AA to the next in the vertical sequence. The AAs in these vertical stacks thus collectively represent a single identifiable region of seismic amplification of a background stratigraphic reflectivity series that can extend vertically for up to ca. $500 \mathrm{~m}$ [1600 ft]. The precise geometry of the stacking pattern varies from 
cluster to cluster, because of the variability in length of the individual superimposed AAs.

The stacked amplitude anomalies observed in the study area closely match similar stacked AAs described by Foschi et al. (2014), who termed them as 'vertical anomaly clusters' (VACs). The hallmark of a VAC is therefore seen to be the vertically stacked composite nature of the amplified region (Figure 5B and $\mathrm{C}$ ). We extend this terminology here, and subdivide VACs into three classes, based on the gross stacking patterns and 3D morphology of the individual AAs comprising the composite anomaly. We define simple VACs in the usage originally proposed by Foschi et al. (2014). However, we introduce two new variants to this category to recognise specific geometrical forms adopted in the vertical stacking, with a progressive tendency to develop discordant geometries with respect to the host stratigraphy. These are defined and described in the following sections, as serrated and discoidal VACs.

\section{Serrated VACs}

Serrated VACs are defined as obliquely stacked AAs, where successively shallower individual AAs exhibit a progressive sideways shift in the locus of amplification (Figure $5 C$ and 7). Serrated VACs differ from the simple VACs described above primarily in their gross stacking pattern, which instead of being vertical with variable overlap, is oblique, with usually quite limited overlap (Figure $5 \mathrm{C}$ and 7 ). In addition, some of the individual AAs within a serrated VAC may even exhibit a discordant geometry to the host reflections. In the study area, the angular discordance of these short AA reflection segments varies from $3^{\circ}$ to $7^{\circ}$ (Figure 7 ). As with the simple VACs, serrated VACs involve amplification of a relative uniform background seismic facies, with no obvious 
stratigraphic discordance explaining the observed obliquity. For example, there are no channels or erosional features in these amplified intervals. Importantly, the primary stratigraphic reflections are continuous in both amplitude-frequency content and stratal geometry across the AAs (Figure 7).

The dimensions of the serrated VACs are generally smaller than for the simple

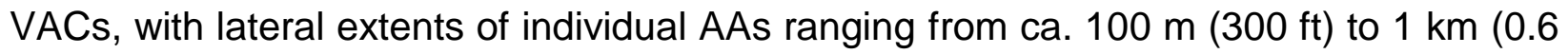
mi). Vertically, the AAs are arranged into clusters that extend vertically up to $700 \mathrm{~m}$ [2300 ft]). The stacking is typically arranged into two oppositely dipping sets of AAs (Figure 7A).

The planform of the individual AAs within the serrated VACS is typically represented by an irregular elliptical ring shape (Figure 7C). In three dimensions, the two oppositely dipping sets of AAs sometimes connect laterally to delineate a grossly funnel-shaped or conical geometry of the amplified region (Figure 5C). The aspect ratio of the ellipse is variable, with the axes ranging between approximately $400 \mathrm{~m}(1300 \mathrm{ft})$ and $5 \mathrm{~km}(3 \mathrm{mi})$. The stratigraphic intervals hosting serrated VACs are commonly deformed by intense polygonal faulting. In these cases, the margin appears more irregular and partly follows the linear patterns defined by the faults (Figure 7B).

\section{Discoidal VACs}

Discoidal VACs are defined as stacked, laterally extensive and continuous acoustically positive or negative amplified reflections, which are discordant to the primary hosting reflections (Figure 5D and 8). They are characterised by a 3D morphology resembling a disc, hence their designation as discoidal VACs (Figure 5D). Although superficially 
similar in some respects to serrated VACs, this third class of VAC is distinctive in the vertical stacking pattern, the $3 \mathrm{D}$ morphology and the lateral extent. These main characteristics will be described in detail below.

Discoidal VACs are characterised by two sets of reflections defining their base and top. The base of the VACs is an acoustically hard reflection and the top is acoustically soft (Figure 8B). The angular discordance of these VACs with the primary hosting reflections ranges from $0.5^{\circ}$ to $10^{\circ}$ but with most examples in the study area ranging from $1^{\circ}$ to $3^{\circ}$. The base and top AAs converge at the margins of the VAC, typically reaching the configuration of a bright spot, concordant with the hosting reflections, and diverge towards its centre, reaching the maximum separation in the middle part of the VAC (Figure 5D and 8B). In three dimensions, the top and the base of the VACs connect laterally to delineate a grossly discoidal shape of the amplified region (Figure 5D).

The discoidal VACs can be differentiated from the serrated VACs also due to their much extended lateral continuity. The maximum lateral dimension of the discoidal VACs is consistently higher than the measurement obtained for the simple and serrated

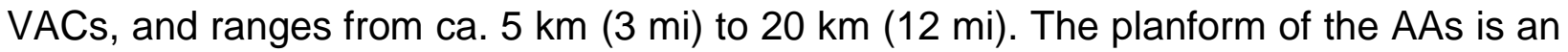
irregular ellipsoidal ring, which is revealed on horizontal time-slices and along mapped horizons (Figure 8A). The aspect ratio of the ellipsoid is variable and generally the axes range between $3 \mathrm{~km}(1.8 \mathrm{mi})$ and $20 \mathrm{~km}(12 \mathrm{mi})$.

The discoidal VACs stack vertically for up to $0.3 \mathrm{~s}$ (corresponding to ca. $300 \mathrm{~m}$ [1000 ft]) (Figure 8A). Typically, these AAs are more laterally extensive and less vertically extensive than the serrated VACs. As with the simple and serrated VACs, 
discoidal VACs are not typically associated with any evidence of erosion, or any other form of stratigraphic discordance, and the primary stratigraphic reflections are continuous in both amplitude content and stratal geometry across the amplified regions.

\section{Quantitative Analysis of the Anomalies}

A combination of instantaneous frequency and AVO analysis was carried out on a subcube of the Sirius-Rigel 3D survey, on the most evident of the AAs, named the Matariki anomaly, in order to evaluate whether the anomalies are due to fluid substitution (Castagna and Swan, 1997; Castagna et al. 2003)

Instantaneous frequency analysis is performed with a workflow based on frequency selection (iso-frequency) and energy filtering. The result of the $12 \mathrm{~Hz}$ isofrequency extraction and filtering (Figure 9) shows that the highest energy at this low frequency value (yellow clusters in figure 9, grey in the black and white version) is clearly associated with the discoidal VAC (base of anomaly cluster) both vertically (in section) and areally (in plan view). The predominance of low frequency values is due to differential absorption of high frequencies: this has been often associated with the presence of gas bearing sediments (Vernik, 1994). The highest frequencies of the seismic bandwidth are adsorbed by the displacement of the gas in the pore space by the seismic waves (Mavko et al., 2003). This effect is termed a frequency shadow or shadow effect (Castagna et al., 2003).

AVO analysis has been performed on pre-stack data (CDP gathers), on a representative seismic section crossing the centre of the Matariki anomaly (Figure 10). Anomalous variations of amplitudes with offset can indicate the presence of gas in the 
sediments (Castagna and Smith, 1994; Castagna and Swan, 1997). The AVO response observed here is based on the classification described by Rutherford and Williams (1989) and displayed following the cross-plot technique (Castagna and Swan, 1997; Castagna et al., 1998). The results for this AVO analysis on this anomaly highlight a patchy class III response. The response is much clearer and more pronounced in the extreme rims of the anomaly (Figure 10).

The AVO analysis performed on the anomaly provides an indication of the fluid content in the hosting sediments, which is sensitive to a minimum saturation threshold (5-10\%) (Domenico, 1974). However, the acoustic response does not allow us to distinguish between low and high gas saturation. AVO analysis has been typically designed for sandstone reservoirs, and similar acoustic effects for low permeability rocks are not as well established. Low gas saturation in sediments characterised by high shale content can be modelled and detected on seismic data with an accurate well calibration (Li, 2004; Li, 2005), which was not available for this study.

In summary, it is considered significant that both the frequency and AVO analysis are compatible with a fluid-related anomaly (gas). It must be considered, however, that the results of this AVO analysis are uncalibrated by wells, and the physical properties of the hosting sediments are not well constrained. This places a limitation on the reliability of the method. Further AVO tests (2D and 3D) in areas with well calibration will potentially reduce the uncertainty of the results.

Although no direct calibration of the Matariki discoidal VAC exist, a similar discoidal VAC, located in Cenozoic deepwater sedimentary succession in the Waka 
area of the CB, has been recently drilled by the well Caravel-1, (Figure 11) (Blanke, 2015). The key results from this well are:

- Two anomalously high amplitude reflections were calibrated by the well in the Eocene: one of which corresponds to an increase in gas derived from a marine source rock, reaching a saturation of $1 \%$;

- Gas readings of up to $4 \%$ have been observed in the Paleocene sediments, immediately below the Waipawa - Tartan black shales (equivalent to Horizon T10). This formation has been associated with good sealing properties. At this level, no clear AA is observed on the seismic data crossing the well location, although regionally most $A A s$ are located below the Waipawa-Tartan black shales and regional seal.

The above observations and drilling results support the presence of gas in the basin, however, due to their non-uniqueness, they need to be evaluated in combination with qualitative observations derived from seismic interpretation in order to account for the origin of the anomalies.

\section{INTERPRETATION OF THE VACS}

The change in acoustic character from background values of the host sediments to the highly amplified reflections referred to as AAs could have a number of different causes, e.g. variations in lithology, porosity, cementation, and fluid (Brown, 2004). The 3D analysis undertaken here shows that the anomalies have geometries that differ from any previously described lithological stacking configuration, with both planform and cross sectional characteristics contrasting markedly with standard seismic facies 
associations (Posamentier et al., 2007). Similarly, the complexity and variety of 3D morphologies observed in the anomalies cannot be due to intrusive bodies of clastic, evaporitic or igneous origin, whose discordant geometries are invariably associated with acoustically hard reflections (see e.g. Cartwright et al., 2007). Rather, the discoidal VACs show a distinct acoustically soft top reflection. Additionally, the relative continuity and limited disruption of the primary bedding reflections enclosed by the serrated and discoidal VACs suggests that the sediments within the anomalous acoustic regions did not undergo significant deformation, again, in marked contrast to that observed for mud volcanoes or other intrusive or extrusive soft-sediment deformation features (Van Rensbergen et al., 2003). Hence a direct lithological explanation is considered a very unlikely fit for the seismic observations.

Diagenesis might offer a suitable explanation for the complex geometries observed. In particular, the cross-stratal geometry of the discoidal VACs (Figures 6, 8 and 9) is reminiscent of reflection geometry linked to diagenesis of biogenic silica (Davies and Cartwright, 2002; Davies et al., 2008). Diagenetic 'fronts' resulting from the transformation of opal A to opal CT and opal CT to quartz can explain the rather complex geometry of the anomalies but cannot explain the negative acoustic impedance contrast observed in the top part of the discoidal VACs.

The above observations, combined with the results from the AVO analysis, are thus sound grounds for interpreting the 'soft' character (negative acoustic impedance contrast) of the top discoidal VAC reflection (Figures 6, 8 and 9), and 'hard' character of the base discoidal VAC reflection with an origin due to gas replacement of the connate waters in the pore space. Gas substitution of the interstitial water is the only 
phenomenon that is able to produce such a plethora of anomalous seismic reflections in relatively undeformed, fairly homogenous deep water sediments. The presence of gas in sediments causes a decrease in acoustic impedance (due to the higher compressibility and lower density) which results in changes in the reflection amplitude. Simple VACs conform to the descriptions of VACs inferred to be due to gas-charged thin hemipelagite units (Foschi et al., 2014), while serrated VACs described closely resemble 'Christmas-tree' gas anomalies attributed to a gas migration front (Ben-Brahim et al., 1999). Discoidal VACs have not previously been reported in the context of gasrelated features and DHIs, possibly because their interpretation on post-stack seismic data may be obscured by seismic artefacts.

Basinal mapping of the simple, serrated and discoidal VACs (Figure 4) shows that the three types of AAs are not isolated, but often combine and cluster vertically and laterally to form composite 3D geometries. The best examples are seen in the SiriusRigel 3D survey in the Matariki anomaly, and in the Waka 3D survey in the CB (named here the Waka anomaly) (Figure 11, 12 and 13). Both Matariki and Waka are assemblages of diverse anomaly types, namely the serrated and discoidal VACs. The assembled AAs can have a total vertical extent of over 1s (ca. $1 \mathrm{~km}$ [0.6 mi]) (Figure 12 and 13) and can laterally extend for over $100 \mathrm{~km}$ (60 mi) (Figure 4). Overall, the arrangement of the different types of VACs is a nearly continuous spectrum (Figure 14): this suggests that gas is widespread in the sediments, and that a comprehensive model explaining what controls VACS distribution could be used to predict how this gas behaves in space and time. 


\section{Controls on the distribution of the VACs}

The different types of VACs are combined in clusters, showing both a vertical and lateral continuum, and they are widespread over a large area of the GSB and less frequently, in the CB (Figure 4). Overall, the complete range of VACs is most evident within the post-rift units, in Late Cretaceous to Late Eocene host sediments, between horizon K100 and T70 (Figure 14). The simple VACs are generally distributed and combined into discrete clusters in the deeper and southern part of the basin (Figure 4). The elongated planform and abrupt lateral terminations of the simple VACs in section, strongly suggests a control by underlying faults in the host unit.

The serrated and discoidal VACs tend to be relatively symmetrical and the evidence of fault focusing of gas migration is quite limited. Variance attributes extracted along horizon $\mathrm{K} 100$ reveal that at least one of these VACs is cross-cut at its base by two NE-SW trending lineaments, roughly parallel to the elongated side of the discoidal body (Figure 15). In section these lineaments can be interpreted as corresponding to the trace of faults, crossing the Cretaceous unit, from the basement to the base of the discoidal VAC. The faults are deep-seated and define the flank of an underlying basement high.

These observations compel us to envisage a partial fault-controlled mechanism of gas migration similar to that described by Foschi et al. (2014) for the VACs in the Falklands Basin. Those authors describe a combination of meter-scale matrix flow and a more extensive, tens of meters scale advective flow of gas along pre-existing fractures and faults within a hemipelagic basin fill. Similarly, Ben-Brahim et al. (1999) suggest that the mechanism for the emplacement of 'Christmas-tree' gas anomalies is a 
combination of a lateral component to fluid movement in high permeability reservoir sediments and vertical movement in lower permeability fractured overburden. The fault bypass route of gas migration is more effective than matrix flow in low permeability sediments (Løseth et al., 2009). Based on these observations, we argue that the emplacement of strata-bound simple VACs is dominated by fault and fracture-controlled advection.

Porosity and permeability variations typically play an important role in controlling the distribution of gas in the host rocks, when the gas flow is regulated by Darcy's Law (Bjørlykke and Gran, 1994; England et al., 1987). In the study area, the VACs preferentially develop at discrete stratigraphic intervals. This tendency to exhibit clustering in a specific stratigraphic interval points to the potential control on the vertical distribution of the VACs by porosity and permeability variations within the overburden.

The Paleocene-Eocene sediments in the area are mainly represented by lowpermeability, high porosity quartz or silica-rich deep-water deposits (Cutter-1 \& Caravel1 wells). Vertical variation of the sealing capacity of these sediments has been measured in the Caravel-1 well (Blanke, 2015), and could be related to subtle changes in permeability. If the gas transport mechanism is dominated by matrix flow, then the variable horizontal and vertical distribution of the VACs could be connected to these subtle grain size and lithology variations, with gas migrating and spreading laterally into the most permeable areas, either as a result of changes in matrix arrangement or fracturing intensity and dimensions.

In the study area, the extensive lateral continuity of the VACs means that they coalesce laterally into a series of clusters, and the final configuration resembles an 
arrangement that is characteristic of migrating gas fronts (Figure 14 and 16). Gas fronts are observed in shallow-burial settings and are typically related to the sulphate reduction zone or to gas hydrates (Moss et al., 2012; Naudts et al., 2010; Otsuka et al., 2011). However, the main stratigraphic intervals of lateral amalgamation in the study area are significantly deeper (several kilometers) than gas fronts reported previously in sedimentary basins. The resemblance of the VACs with gas fronts could instead indicate an increased capacity of specific stratigraphic intervals to act as 'storage', where the lateral gas dispersion is at its maximum, capped by local baffles, where the dispersion of the anomalies is either inhibited or controlled by bypass features such as faults. This enables us to subdivide the stratigraphy into packages that have the tendency to promote storage or bypass of gas (Figure 16). We prefer not to use the terms reservoir and seal in this context, simply because we wish to focus attention more on the flow properties at the seismic scale rather than at the core scale.

In the storage intervals, upward gas flux is retarded by the capacity of numerous thin layers to host some degree of gas saturation generating laterally widespread anomalies. The bypass levels, conversely, would mainly act to convey the gas from a deeper to a shallower storage level, generating anomalies only strictly related to faults and with limited lateral extent. We identify three main storage levels where the anomalies are laterally widespread, respectively bounded by the horizons: K100-T00, T05-T07 (to T10), T50-T60 (Figure 16). Correlation of these layers with the regional stratigraphy places them as immediately following the maximum regression of delta or coastal systems on the shelf (Constable et al., 2013), which could also be associated to the maximum distal reach of the coarser grained sediments into the basin. In these 
specific stratigraphic intervals, especially in level K100-T00 and T05-T10, the gas would tend to migrate laterally and cause the anomalies to amalgamate until forming a frontlike configuration.

Bypass levels are occasionally hosted in polygonally faulted intervals, such as between horizons T20 and T50 (Figure 13). Polygonal faulting could actively contribute to the vertical component of gas migration, or might merely be correlated with the occurrence of fine-grained lithologies, which typically host this type of soft-sediment deformation (Cartwright and Dewhurst, 1998). Polygonal faults act as local baffles to lateral flow, or even as lateral seals, as can be inferred by the abrupt termination of the margin of the anomalies against these faults (Figure 6).

\section{Sequential emplacement of the VACs}

We propose a sequential, step-wise evolutionary model that can explain the transition between the different types of gas-related VACs in the Great South and Canterbury basins (Figure 5):

A) From a basal point or linear feeding source the gas impinges at the base of the most permeable intervals, where it spreads laterally, forming a columnar stack of bright spots (Figure 5A).

B) As the gas feeding progresses, horizontal permeability might predominate over vertical permeability and allow the gas to migrate laterally, to form laterally extensive simple VACS (Figure 5B). The lateral extent of the gas can still be controlled by faults, acting as baffles. The gas-charged layers are mostly disconnected at this stage. Simple 
VACs would therefore represent a juvenile stage of gas migration, immediately following the bright spot formation.

C) The serrated VACs develop sequentially after the simple VACs have formed, when the gas-charged layers become interconnected if multiple simple VACs partially merge (Figure 5C). The gas saturates the sediments more comprehensively; the gas-charged layers become mostly interconnected, in the part nearest to the feeding points. The high reflectivity observed at the fringes, with juxtaposition of soft and hard boundaries, reveals that the interconnection is limited to the central part while the fringes are still disconnected. The partial cross-stratal geometry highlights this partial or incomplete interconnection amongst gas-charged thin layers.

D) The discoidal VACs form once the full interconnection of the gas-charged layers is attained, and the homogeneous distribution of gas generates a continuous high amplitude cross-cutting reflection (Figure 5D). The overall seismic polarity of the discoidal VACs (soft top and hard base) points to a continuity of the gas content in the hosting sediments, enclosed by the discoidal VACs. Therefore, serrated and discoidal VACs would represent a more evolved stage of gas migration, following the emplacement of bright spots and simple VACs.

In this model, we assume that the stages $A$ to $C$ represent the dynamic state of gas migration, until full equilibrium is reached at stage $D$, i.e. once the pressure of the pore waters in the hosting sediments is in equilibrium with fluxes of the gas charge. The change from disconnected to interconnected state can be determined by subtle changes in porosity and permeability in the hosting sediments, such that the distinction 
between gas storage and bypass layers is only valid at certain stages of the process, pressure or gas flux conditions.

A caveat should be added to this model, due to the limitations of seismic imaging: similarly to what has been recently described for gas hydrate fronts (Hillman et al., 2017), the discoidal VACs could represent the constructive interference of horizontal gas-brine contacts at the margin of the anomaly, rather than a single interface, and this depends on the thickness of the storage layers and the vertical resolution of seismic data. Based on this analogy, we suggest that the continuity of the discoidal VACs is strictly dependent on the seismic imaging of stacked horizontal gas-brine contacts rather than representing a fully continuous tilted gas-water contact per se. Our observations indicate that the transition from simple to serrated and discoidal VACs can be used as a way to detect the relative evolutionary stage of the migration process, and give an indication of the overall lateral vs vertical migration and leakage paths in the basin.

\section{DISCUSSION}

The observation of such a wide range of laterally extensive gas-related seismic AAs in the GSB and $C B$ raises the questions of how is the gas originated, what is its composition and relationship with a possible petroleum system in the area. Gases of different composition can create a similar response on stacked seismic data, therefore, the possible origin of the gas needs to be evaluated based on the setting of the fluids and hosting sediments. The important drilling results of the Caravel-1 well in the CB sheds some light on the gas composition associated with the VACs in the study area. 
Fluid inclusion analysis shows dry gas, wet gas and condensate responses in the deeper part of the section (Cretaceous), suggesting the presence of a thermogenic petroleum system at some time in the past basin history. These well results confirm the presence of low saturation thermogenic gas, in one case directly associated with the AAs.

However, XRD data in the Caravel-1 well also recorded (in core analysis) the presence a $9 \%$ concentration of dawsonite and the Opal CT-Quartz diagenetic transformation, at a shallower level above the Eocene anomalies. Dawsonite is interpreted by the operator as being diagnostic for the diagenesis of kaolinite in the presence of $\mathrm{Na}$ and $\mathrm{CO}_{2}$ (Blanke, 2015). The occurrence of significant fractions of dawsonite might point to the past presence of $\mathrm{CO}_{2}$ within the sediments, and its possible role in generating the seismic amplitude anomalies. Nevertheless, the geological context of the VACs in the study area provides several lines of argument that point more firmly to thermogenic hydrocarbon gases than to $\mathrm{CO}_{2}$.

Firstly, there is no evidence of volcanic or intrusive igneous activity in the likely time period for the gas migration into the VACs. Hydrothermal vents and sills are present in the area, but are dated in the GSB as Late Cretaceous to Early Cenozoic (Figure 12). This significantly pre-dates the emplacement of the VACs, which extend upwards stratigraphically into Oligocene sediments. It should be noted that there is a strong spatial correlation between the presence of the sills in the sediments and the VACs (Figure 13 and 15). This suggests that even long after the emplacement of sills and vents, they may have acted as seal bypass systems for the later phase of gas migration, such as described for the Laggan-Tormore fields in the North Sea Basin 
(Rateau et al., 2013). Sills might therefore play an important part in the migration route and provide avenue for an advective component of the gas flow along the fractured conduits.

Secondly, gas kitchens for the two most likely source intervals in the GSB show a strong spatial correlation with the basinal mapping of the VACs from the $2 \mathrm{D}$ and $3 \mathrm{D}$ seismic data (Figure 4). Basin modelling using the syn-rift source rock distribution (proven in previous discoveries in the area) suggests that the GSB has been in the active thermogenic gas generation window from the latest Cretaceous (due to the high heat flow during rifting), to the present day, with a main peak of gas expulsion around the Eocene (Shell New Zealand, pers. comm., 2014). The shallowest and therefore youngest indicators of fluid expulsion, related to the gas anomalies, are observed in the Matariki area (Figure 13), and in a few other examples, to extend upwards as shallow as the Oligocene and possibly the Miocene intervals. This suggests that they might have been generated within or prior to the Miocene, or that the Miocene to Recent interval represents the top seal to the migrating gas.

The presence of another potential source rock is considered within the coalbearing sequences of the Murihuku terrane. The anomalies covered by the Sirius-Rigel 3D survey are mostly located above this terrane type (Figure 1), while the Caravel and Waka anomalies in the $\mathrm{CB}$, as well as other anomalies in the south-western part of the GSB (2D seismic coverage) are located above other basement terranes, therefore excluding a direct control between basement type and anomaly emplacement. However, the presence of coal-bearing sequences in the Murihuku basement stratigraphy could have locally contributed to the generation of the gas forming the 
anomalies. These general observations suggest that the emplacement of the VACs is compatible with the wide time range of modelled hydrocarbon generation in the GSB. Based on these observations, and on the analogy with the Caravel-1 well, the most likely origin of the gas in the study area is thermogenic.

\section{CONCLUSIONS}

- An exceptional range of composite AAs (amplitude anomalies) have been identified across two large sedimentary basins, the Great South and Canterbury Basin, offshore New Zealand.

- The AAs are interpreted as caused by gas, based on the combination of AVO and other attribute analyses, and classified as VACs (Vertical Anomaly Clusters). We update the existing terminology by defining three different types of VACs, i.e. simple, serrated and discoidal VACs, in order to capture the complexity of the stacked and composite anomalies identified in the region. The serrated and discoidal VACs are here described for the first time.

- The possible sources generating the VACs are believed to be thermogenic gas or $\mathrm{CO}_{2}$. The distribution of the VACs is generally correlated with maximum burial regions of the most prospective source rock intervals. Therefore, a thermogenic origin for the gas is the preferred interpretation based on timing, volumes and spatial coincidence of the VACs with the hydrocarbon kitchen. Two main mechanisms are advocated for migration: advection (along faults and sills) and matrix flow (along pores). Low-permeability (and possibly, high porosity) sediments are the main vehicle for basin wide gas migration. Matrix flow appears 
to occur in these relatively low-permeability sediments with a higher efficiency than previously seen in basins. We suggest that the shape of the composite VACs is directly controlled by gas flux and by probably quite subtle variations in physical properties of the host sediments.

- The documentation of a wide range of gas-related AAs developed in a relatively uniform lithostratigraphy and in similar basinal contexts allows us to infer a migration sequence based on the morphostructural and geophysical characteristics of the anomalies. Migration paths and migration evolution is indicated by the transition between the juvenile (simple) to the more evolved (serrated and discoidal) VAC types. 


\section{REFERENCES}

Andresen, K. J., 2012, Fluid flow features in hydrocarbon plumbing systems: What do they tell us about the basin evolution?: Marine Geology, v. 332-334, p. 89-108.

Andresen, K. J., and M. Huuse, 2011, 'Bulls-eye' pockmarks and polygonal faulting in the Lower Congo Basin: Relative timing and implications for fluid expulsion during shallow burial: Marine Geology, v. 279, p. 111-127.

Bache, F., N. Mortimer, R. Sutherland, J. Collot, P. Rouillard, V. Stagpoole, and A. Nicol, 2014, Seismic stratigraphic record of transition from Mesozoic subduction to continental breakup in the Zealandia sector of eastern Gondwana: Gondwana Research, v. 26, p. 1060-1078.

Bear, J., 1972, Dynamics of fluids in porous media, American Elsevier Publishing Company, $780 \mathrm{p}$.

Ben-Brahim, L., R. Petton, M. Couderc, and A. Djamhoer, 1999, Characterisazion of seismic anomalies using converted waves: a case history from East Natuna Basin: 27th IPA Annual Convention Proceedings, p. 1-9.

Berndt, C., 2005, Focused fluid flow in passive continental margins: Philosophical Transactions of the Royal Society A: Mathematical, Physical and Engineering Sciences, v. 363, p. 2855-2871.

Bertoni, C., and J. Cartwright, 2015, Messinian evaporites and fluid flow: Marine and Petroleum Geology, v. 66, p. $165-176$.

Bjørkum, P. A., O. Walderhaug, and P. H. Nadeau, 1998, Physical constraints on hydrocarbon leakage and trapping revisited: Petroleum Geoscience, v. 4, p. 237-239.

Bjørlykke, K., and K. Gran, 1994, Salinity variations in North Sea formation waters: implications for largescale fluid movements: Marine and Petroleum Geology, v. 11, p. 5-9.

Blanke, S. J., 2015, Caravel-1: Lessons Learned in the Deepwater Canterbury Basin: International Conference and Exhibition, Melbourne, Australia 13-16 September 2015, p. 519-519.

Brooks, J. M., H. B. Cox, W. R. Bryant, M. Kennicutt, R. G. Mann, and T. J. McDonald, 1986, Association of gas hydrates and oil seepage in the Gulf of Mexico: Organic Geochemistry, v. 10, p. 221-234.

Brown, A. R., 2004, Interpretation of Three-Dimensional Seismic Data: AAPG Memoir/SEG Investigations in Geophysics No. 9.

Calvès, G., M. Huuse, A. Schwab, and P. Clift, 2008, Three-dimensional seismic analysis of high-amplitude anomalies in the shallow subsurface of the northern Indus Fan: Sedimentary and/or fluid origin: Journal of Geophysical Research B: Solid Earth, v. 113.

Cartwright, J., M. Huuse, and A. Aplin, 2007, Seal bypass systems: AAPG Bulletin, v. 91, p. 1141-1166.

Cartwright, J. A., and D. N. Dewhurst, 1998, Layer-bound compaction faults in fine-grained sediments: Bulletin of the Geological Society of America, v. 110, p. 1242-1257.

Castagna, J. P., and S. W. Smith, 1994, Comparison of AVO indicators: a modeling study: Geophysics, v. 59 , p. 1849-1855.

Castagna, J. P., S. Sun, and R. W. Siegfried, 2003, Instantaneous spectral analysis: Detection of lowfrequency shadows associated with hydrocarbons: The Leading Edge, v. 22, p. 120-127.

Castagna, J. P., and H. W. Swan, 1997, Principles of AVO crossplotting: The Leading Edge, v. 16, p. 337.

Castagna, J. P., H. W. Swan, and D. J. Foster, 1998, Framework for AVO gradient and intercept interpretation: Geophysics, v. 63, p. 948-956.

Chadwick, R. A., R. Arts, O. Eiken, G. A. Kirby, E. Lindeberg, and P. Zweigel, 2004, 4D Seismic Imaging of an Injected C02 Plume at the Sleipner Field, Central North Sea, Geological Society, London, Memoirs, 29(1), p. 311-320.

Chadwick, R. A., B. P. Marchant, and G. A. Williams, 2014, CO2 storage monitoring: leakage detection and measurement in subsurface volumes from 3D seismic data at Sleipner: Energy Procedia, v. 63, p. 4224-4239. 
Constable, R., D. Lang, and T. Allan, 2013, H. Development of a sequence stratigraphic framework in the Great South basin: Advantage NZ: 2013 Petroleum Conference. Wellington: NZPAM, p. 1-21.

Davies, R. J., and J. Cartwright, 2002, A fossilized Opal A to Opal C/T transformation on the northeast Atlantic margin: Support for a significantly elevated palaeogeothermal gradient during the Neogene?: Basin Research, v. 14, p. 467-486.

Davies, R. J., N. R. Goulty, and D. Meadows, 2008, Fluid flow due to the advance of basin-scale silica reaction zones: Geological Society of America Bulletin, v. 120, p. 195-206.

Domenico, S., 1974, Effect of water saturation on seismic reflectivity of sand reservoirs encased in shale: Geophysics, v. 39, p. 759-769.

Downey, M. W., 1984, Evaluating seals for hydrocarbon accumulations: AAPG Bulletin, v. 68, p. 17521763.

England, W., A. Mackenzie, D. Mann, and T. Quigley, 1987, The movement and entrapment of petroleum fluids in the subsurface: Journal of the Geological Society, v. 144, p. 327-347.

Heggland, R., 1997, Detection of gas migration from a deep source by the use of exploration 3D seismic data: Marine Geology, v. 137, p. 41-47.

Heggland, R., 1998, Gas seepage as an indicator of deeper prospective reservoirs. A study based on exploration 3D seismic data: Marine and Petroleum Geology, v. 15, p. 1-9.

Heggland, R., E. Nygaard, and J. W. Gallagher, 1996, Techniques and experiences using exploration 3D seismic data to map drilling hazards: Offshore Technology Conference p. 119-127.

Hillman, J. I., A. E. Cook, D. E. Sawyer, H. M. Küçük, and D. S. Goldberg, 2017, The character and amplitude of 'discontinuous' bottom-simulating reflections in marine seismic data: Earth and Planetary Science Letters, v. 459, p. 157-169.

Ho, S., J. Cartwright, and P. Imbert, 2012, Vertical evolution of fluid venting structures in relation to gas flux, in the Neogene-Quaternary of the Lower Congo Basin, Offshore Angola: Marine Geology, v. 332, p. 40-55.

Hovland, M., 1983, Elongated depressions associated with pockmarks in the Western Slope of the Norwegian Trench: Marine Geology, v. 51, p. 35-46.

Hovland, M., and A. G. Judd, 1988, Seabed pockmarks and seepages: impact on geology, biology and the marine environment: Springer.

Hustoft, S., S. Bünz, J. Mienert, and S. Chand, 2009, Gas hydrate reservoir and active methane-venting province in sediments on young oceanic crust in the Fram Strait, offshore NW-Svalbard: Earth and Planetary Science Letters, v. 284, p. 12-24.

Judd, A. G., and M. Hovland, 2007, Seabed Fluid Flow : The Impact on Geology, Biology and the Marine Environment: Cambridge, Cambridge University Press, $492 \mathrm{p}$.

Li, M.-C., 2004, Basic principles of migration and hydrocarbon exploration: Earth Science, v. 29, p. 379383.

Li, Y., 2005, A study on partial gas saturation due to lithological effects, SEG Technical Program Expanded Abstracts 2005, Society of Exploration Geophysicists, p. 301-304.

Løseth, H., M. Gading, and L. Wensaas, 2009, Hydrocarbon leakage interpreted on seismic data: Marine and Petroleum Geology, v. 26, p. 1304-1319.

Lu, H., C. S. Fulthorpe, and P. Mann, 2003, Three-dimensional architecture of shelf-building sediment drifts in the offshore Canterbury Basin, New Zealand: Marine Geology, v. 193, p. 19-47.

Mavko, G., T. Mukerji, and J. Dvorkin, 2003, The Rock Physics Handbook: Tools for Seismic Analysis in Porous Media: Cambridge, Cambridge University Press.

Mazzini, A., R. Jonk, D. Duranti, J. Parnell, B. Cronin, and A. Hurst, 2003, Fluid escape from reservoirs: implications fromcold seeps, fractures and injected sands Part I. The fluid flow system: Journal of Geochemical Exploration, v. 78, p. 293-296. 
Meldahl, P., R. Heggland, B. Bril, and P. de Groot, 2001, Identifying faults and gas chimneys using multiattributes and neural networks: The Leading Edge, v. 20, p. 474-482.

Milkov, A. V., G. E. Claypool, Y. J. Lee, and R. Sassen, 2005, Gas hydrate systems at Hydrate Ridge offshore Oregon inferred from molecular and isotopic properties of hydrate-bound and void gases: Geochimica et Cosmochimica Acta, v. 69, p. 1007-1026.

Moss, J. L., J. Cartwright, and R. Moore, 2012, Evidence for fluid migration following pockmark formation: Examples from the Nile Deep Sea Fan: Marine Geology, v. 303-306, p. 1-13.

Naudts, L., J. Greinert, J. Poort, J. Belza, E. Vangampelaere, D. Boone, P. Linke, J.-P. Henriet, and M. De Batist, 2010, Active venting sites on the gas-hydrate-bearing Hikurangi Margin, off New Zealand: Diffusive-versus bubble-released methane: Marine Geology, v. 272, p. 233-250.

Ostanin, I., Z. Anka, R. di Primio, and A. Bernal, 2013, Hydrocarbon plumbing systems above the Snøhvit gas field: Structural control and implications for thermogenic methane leakage in the Hammerfest Basin, SW Barents Sea: Marine and Petroleum Geology, v. 43, p. 127-146.

Otsuka, H., S. Morita, M. Tanahashi, S. Nagakubo, and J. Ashi, 2011, Possible migration front of gasrelated fluid inferred from 3D reflection seismic survey in the eastern Nankai Trough: Journal of the Japanese Association for Petroleum Technology, v. 76, p. 39-42.

Party, S. S., 1999, Leg 181 summary: Southwest Pacific paleoceanography: Proc. ODP Init. Rep, p. 1-80.

Posamentier, H. W., R. J. Davies, J. A. Cartwright, and L. J. Wood, 2007, Seismic geomorphology - An overview, p. 1-14.

Pryer, L., J. Weir, T. Debacker, and K. Romine, 2013, Interpretation of basement: NZ ECS SEEBASE: Advantage New Zealand Petroleum Summit, April 2013.

Rao, Y., C. Subrahmanyam, A. Rastogi, and B. Deka, 2001, Anomalous seismic reflections related to gas/gas hydrate occurrences along the western continental margin of India: Geo-Marine Letters, v. 21, p. $1-8$.

Rateau, R., N. Schofield, and M. Smith, 2013, The potential role of igneous intrusions on hydrocarbon migration, West of Shetland: Petroleum Geoscience, v. 19, p. 259-272.

Roberts, H., P. Aharon, R. Carney, J. Larkin, and R. Sassen, 1990, Sea floor responses to hydrocarbon seeps, Louisiana continental slope: Geo-Marine Letters, v. 10, p. 232-243.

Roberts, H., B. Kohl, D. Menzies, and G. Humphrey, 1999, Acoustic wipe-out zones-a paradox for interpreting seafloor geologic/geotechnical characteristics (an example from Garden Banks 161): Offshore Technology Conference.

Roberts, H. H., D. J. Cook, and M. K. Sheedlo, 1992, Hydrocarbon seeps of the Louisiana continental slope: Seismic amplitude signature and sea floor response. Gulf Coast Association of Geological Societies Transactions, Vol. 42, Pages 349-361.

Roberts, W., and R. Cordell, 1980, Problems of petroleum migration: introduction: AAPG Series in Geology, v. 10, p. 6-8.

Schattner, U., M. Lazar, D. Harari, and N. Waldmann, 2012, Active gas migration systems offshore northern Israel, first evidence from seafloor and subsurface data: Continental Shelf Research, v. 48, p. 167-172.

Sela-Adler, M., B. Herut, I. Bar-Or, G. Antler, E. Eliani-Russak, E. Levy, Y. Makovsky, and O. Sivan, 2015, Geochemical evidence for biogenic methane production and consumption in the shallow sediments of the SE Mediterranean shelf (Israel): Continental Shelf Research, v. 101, p. 117-124.

Serié, C., M. Huuse, N. H. Schødt, J. M. Brooks, and A. Williams, 2017, Subsurface fluid flow in the deepwater Kwanza Basin, offshore Angola: Basin Research, v. 29, p. 149-179.

Sheriff, R. E., 1975, Factors affecting seismic amplitudes: Geophysical Prospecting, v. 23, p. 125-138.

Todd, D., 1980, Groundwater: Hydrology, 2nd Edition, John Willey and Sons, 315 p.

Van Rensbergen, P., R. R. Hillis, A. J. Maltman, and C. K. Morley, 2003, Subsurface sediment mobilization: Introduction, p. 1-8. 
Vernik, L., 1994, Hydrocarbon-generation-induced microcracking of source rocks: Geophysics, v. 59, p. 555-563.

Wandres, A. M., and J. D. Bradshaw, 2005, New Zealand tectonostratigraphy and implications from conglomeratic rocks for the configuration of the SW Pacific margin of Gondwana: Geological Society, London, Special Publications 246.1, 179-216.

Widess, M., 1973, How thin is a bed?: Geophysics, v. 38, p. 1176-1180.

Claudia Bertoni is Shell Post-doctoral Research Associate at the University of Oxford. She holds BSc and MSc in Geology from University of Rome and a PhD in Basin Dynamics from Cardiff University. She worked for Repsol in Mediterranean and AsiaPacific Exploration and New Ventures from 2006-2013. Her research interests are in basin dynamics, fluid flow and evaporites.

Joe Cartwright is Professor of Earth Sciences at the University of Oxford. He graduated with a BA and D Phil in Geology from the University of Oxford in 1988. He worked for Shell International as an exploration geophysicist from 1980-1984. His current interests embrace the seismic characterisation of mudrocks as seals, mechanisms of hydrocarbon migration and fracture development in shales.

Martino Foschi is a post-doctoral research associate and manager of the Shell Geoscience Laboratory at the University of Oxford. He received a BS in Geology and MS in Exploration Geophysics from the University of Pisa and a PhD in Geology from the Cardiff University. His research focuses on the understanding of fluid flow in sedimentary basins and across seals.

Joe Martin is a Senior Exploration Geoscientist with Shell, Kuala Lumpur, working AsiaPacific Regional Ventures including Brunei, Thailand and Philippines. He holds a B.Sc. in geology and petroleum geology from University of Aberdeen, UK, and a Ph.D in geology from University of Manchester, UK. His research interests are in stratigraphy, sedimentology and regional models of the late Paleozoic ice age. 


\section{FIGURE CAPTIONS}

Figure 1 - Location of study area, indicating seismic and well dataset selected for this study. Black boxes indicate 3D seismic surveys; grey lines indicate 2D seismic lines. The colour shaded areas indicate the different basement terranes according to Wandres and Bradshaw (2005) and Pryer et al. (2013).

Figure 2 - Tie of the seismic data in the Sirius-Rigel 3D survey to the Tara- 1 and Toroa-1 wells, which drilled an almost complete stratigraphic section, down to the Cretaceous sediments. The Murihuku reflective basement terrane is observed in the NE part of the section, while the other terranes imaged are nearly acoustically transparent. Nomenclature of seismic horizons is largely based on Constable et al. (2013).

Figure 3 -Seismic section across the Sirius-Rigel 3D survey, showing several anomalous high amplitude seismic reflections (AAs) in the post-rift series (horizons K50 to T70). The Paleocene and Eocene units (K100 to T70) are the main focus of this study. Location of section is in Figure 1.

Figure 4 - Map showing the basement configuration mainland of the New Zealand South Island. This basement map has been provided by the Shell New Zealand Team. Overlying on the basement map, the black boxes indicate the Sirius-Rigel and Waka 3D seismic surveys. The projected outline of the main VACs observed on seismic data is indicated with dashed lines for the serrated and discoidal VACs a dotted line for the simple VACs. The Matariki and Waka VACs assemblages are highlighted with their respective initials ( $\mathrm{M}$ and $\mathrm{W}$ ). The thick white line marks the boundaries of the modelled extended hydrocarbon kitchen in the Great South Basin, based on potentially generating syn-rift intervals (Shell NZ Team, pers. comm., 2014). 
Figure 5-3D block diagram showing, from $A$ to $D$, the sequential transition between the different types of VACs in the Great South and Canterbury Basins. A and B: simple VACs; C: serrated VAC; D: Discoidal VAC (zoom shows thin bed effect). The arrows indicate the gas flow direction within the sediments. See text for detailed explanation.

Figure 6 - Examples of simple VACs. A: Maximum amplitude extraction at horizon T00. Anomalies are highlighted by the red colours in the colour display of the figure, and by the light grey colour in the black and white display of the figure. Note the ribbon-shaped to irregularly elliptical morphology of these VACs, commonly with a single dominant trend (N-S to NW-SE) adopted by their long axes, consistent with some form of fault control on geometry. B and C: Seismic sections crossing two examples of simple VACs. Note that the simple VACs stack vertically into closely spaced groups that exhibit a significant degree of overlap from one individual AA to the next in the vertical sequence. Location of Figures $6 \mathrm{~B}$ and $\mathrm{C}$ is shown in Figure $6 \mathrm{~A}$.

Figure 7 - Examples of serrated VACs A and B: Seismic sections showing the main characteristics of serrated VACs. The main individual AAs are indicated by the black arrows. Note that successively shallower individual, obliquely stacked AAs exhibit a progressive sideways shift in the locus of amplification, and individual AAs within a serrated VAC may exhibit a discordant geometry to the host reflections. Location is shown in Figure 1. B: Time slice showing a combination of maximum amplitudes (black line with yellow fill in the colour display, white fill in the B/W display) and variance (greyscale). The variance shows the polygonal faults while the maximum amplitude shows the outline of the serrated VAC in plan view, with the typical irregular elliptical ring shape. Location of the time slice is indicated in Figure 7A. 
Figure 8 - Examples of discoidal VACs. A: Maximum amplitude extraction at the dotted line indicated in Figure 8B (this is a composite horizon following the top of the discoidal VAC and a stratigraphic horizon in the dim zone; this cross-stratal horizon is designed to best highlight the differences in amplitude between the amplitude anomaly and the background signal). This attribute shows the typical ellipsoidal planform of the discoidal VACs. B: Seismic section showing the main characteristics of discoidal VACs, i.e.: the presence of two sets of reflections defining their base and top, the base being an acoustically hard reflection and the top acoustically soft; and the angular discordance of these VACs with the primary hosting reflections. Location of the section is indicated in Figure $8 \mathrm{~A}$ and 13.

Figure 9 -Volumetric isofrequency extraction (12 Hz, 1.2 cycles) carried out on the Matariki anomaly: the yellow dots on the colour display, and grey dots on the B/W display highlight the high energy, low frequency content in the sub volume selected. A) Side view, with thin lines indicating multi-z interpretation of the Matariki anomaly. B) View from the top, with thick lines (red in the colour display, white in the B/W display) representing the projected maximum extent of the basal and top discoidal VAC of the Matariki anomaly, and an adjunct AA. The result of the $12 \mathrm{~Hz}$ iso-frequency extraction and filtering shows that the highest energy at this low frequency value is clearly associated with the discoidal VAC (base of anomaly cluster) both vertically (in section) and areally (in plan view). Location of the Matariki anomaly is shown in Figure 4.

Figure 10 - AVO analysis performed on pre-stack data (CDP gathers), on a representative seismic section crossing the centre of the Matariki anomaly. A: InterceptGradient diagram showing the selection of the top Class III (grey squares) and base 
Class III (white squares) AVO anomaly, outside the background signal. B: AVO results displayed on the original seismic section, showing a match of the top Class III and base Class III AVO anomaly analysis with the margins of the basal discoidal VAC. Overall, the AVO response is patchy - see discussion in text.

Figure 11 - Seismic section across the Waka and the Caravel-1 anomalies (AAs), in the Waka 3D survey. The Caravel-1 well drilled a discoidal VAC, located in Cenozoic deepwater sedimentary succession of the Canterbury Basin (details in the text). The approximate location of the Caravel-1 well is taken from Blanke (2015).

Figure 12 - Examples of serrated and discoidal VACs in the Waka 3D area. A: seismic section across the 3D survey, showing the vertical clustering of serrated and discoidal VACs. Note the continuity of the primary stratigraphic reflections across the both types of VACs. B: 3D visualization of the outline of the Waka VAC assemblage.

Figure 13 - Examples of serrated and discoidal VACs in the Matariki 3D area. A: seismic section across the Sirius-Rigel 3D survey, showing the vertical clustering of serrated and discoidal VACs. Note the continuity of the primary stratigraphic reflections across the both types of VACs. B: 3D visualization of the outline of the Matariki VAC assemblage, formed by the top discoidal VAC, the mid serrated VAC, and the basal discoidal VAC.

Figure $14-A$ : Seismic section across the Sirius-Rigel 3D survey, showing examples of the VACs and the lateral and vertical transition amongst them. Overall, the arrangement of the different types of VACs is a nearly continuous spectrum (Figure 14): this suggests that gas is widespread in the sediments, in a front-like distribution (dotted line). B: Zoom 
of the seismic section shown in Figure 14A, showing the detailed interpretation of the different types of adjacent VACs.

Figure 15 - A) Seismic section across the Matariki VACs assemblage, in an eccentric position to its centre. Note the presence of two main lineaments that can be interpreted as corresponding to the trace of faults, crossing the Cretaceous unit, from the basement to the base of the discoidal VAC. The faults are deep-seated and define the flank of an underlying basement high. B: Variance attribute extracted along horizon K100 reveals the trace of the two NE-SW trending lineaments, which are roughly parallel to the main axis of the Matariki basal discoidal VAC.

Figure 16 - Schematic diagram illustrating the possible correlation of the mapped horizons with porosity and permeability variations, based on long-distance correlation with the wells located on the shelf (Constable et al., 2013). This correlation is superimposed on the vertical distribution of the anomalies observed in the deep GSB. On the right side of the figure, a column summarizing the vertical distribution of the anomalies, and their hypothetical relationship with presence of gas in the sediments is shown. The extensive lateral continuity of the VACs means that they coalesce laterally into a series of clusters, and the final configuration resembles an arrangement that is characteristic of a migrating gas front (dashed line). 


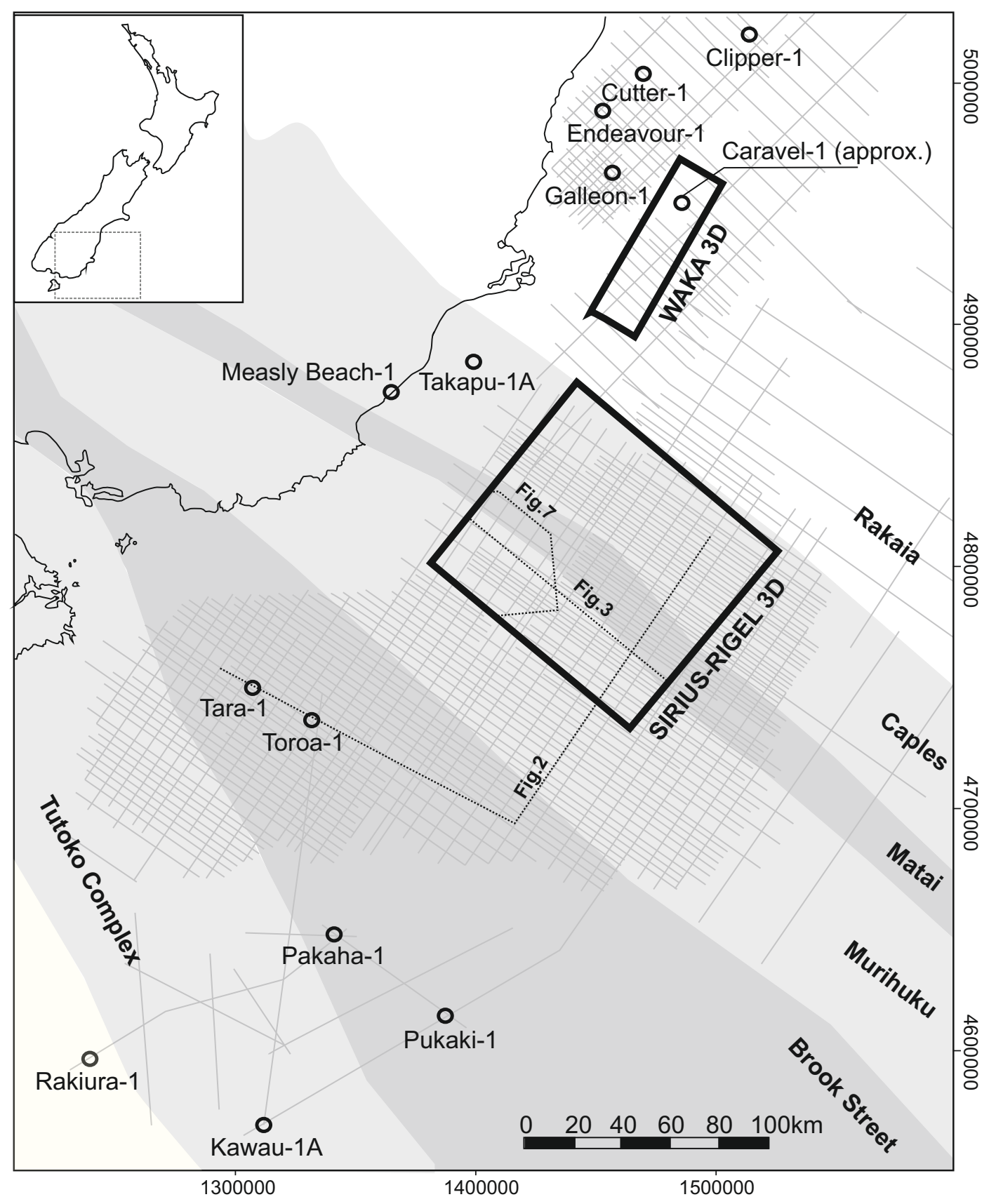

Figure 1 


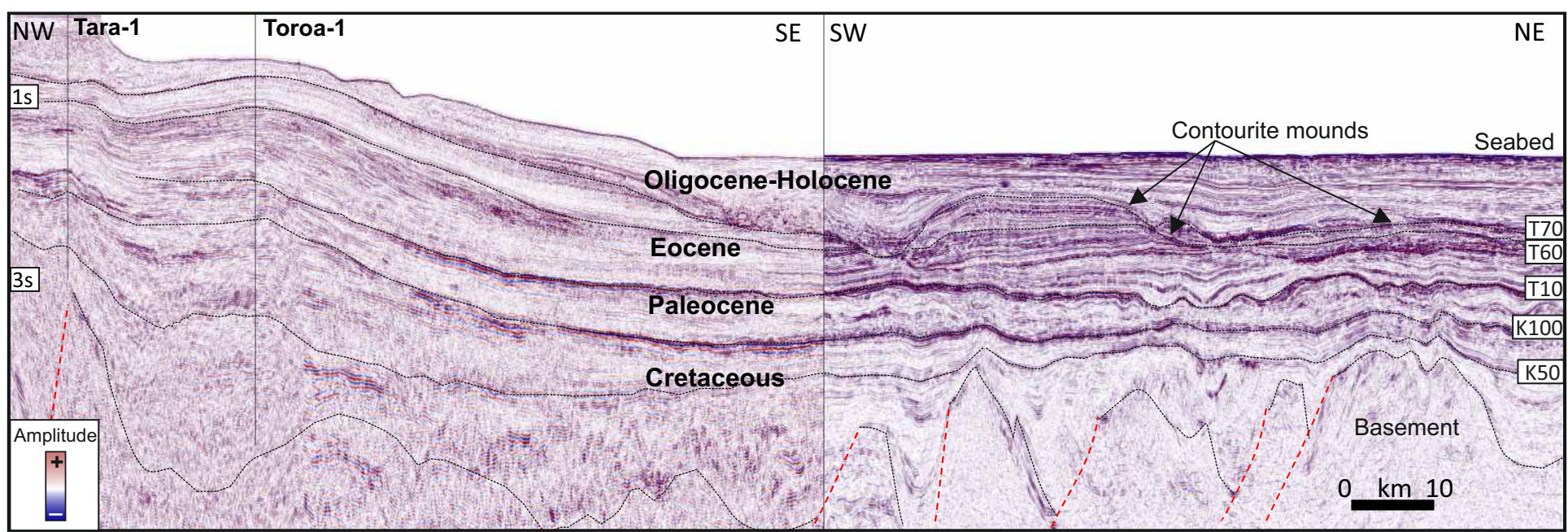

Figure 2 


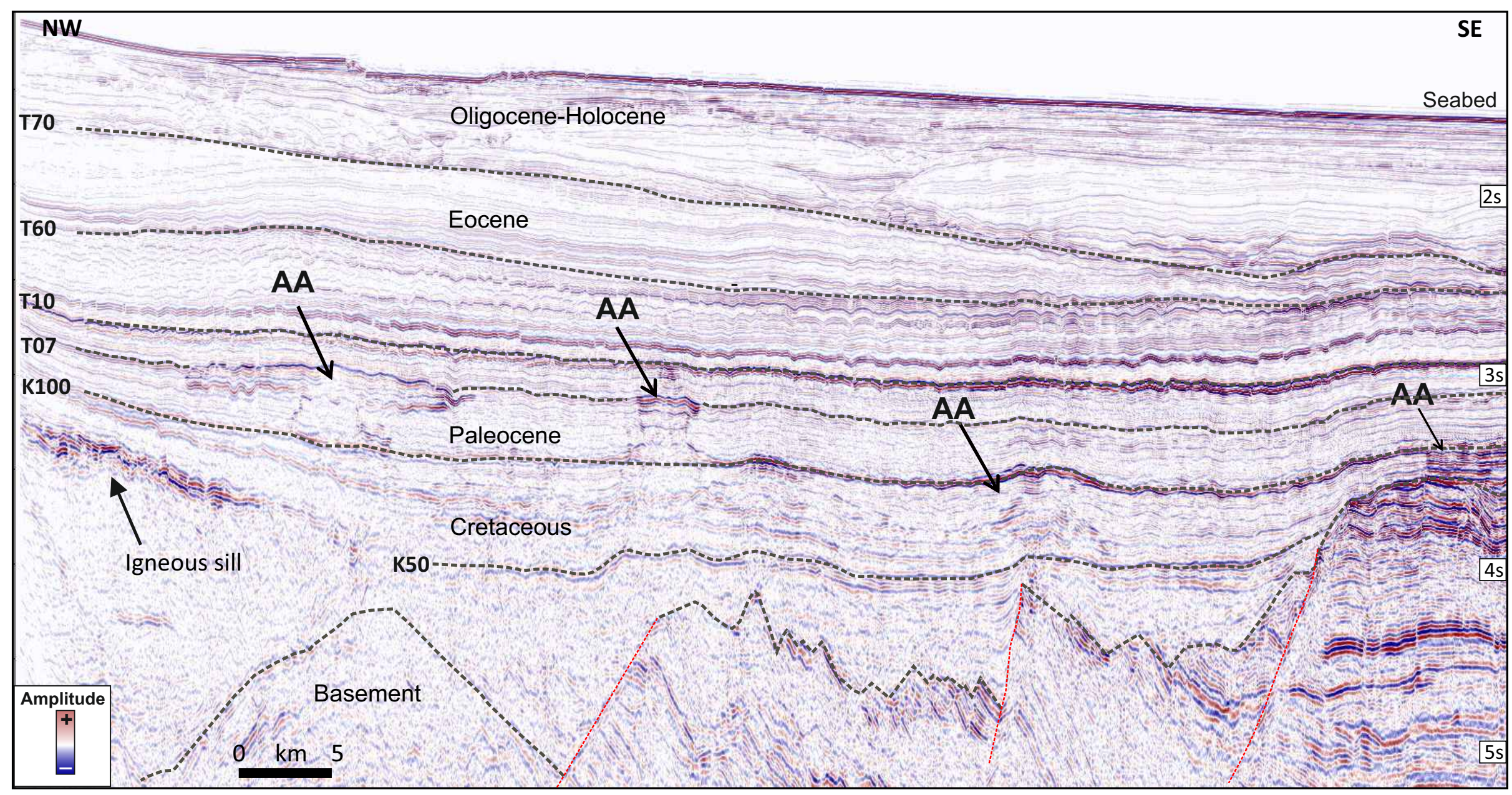

Figure 3 


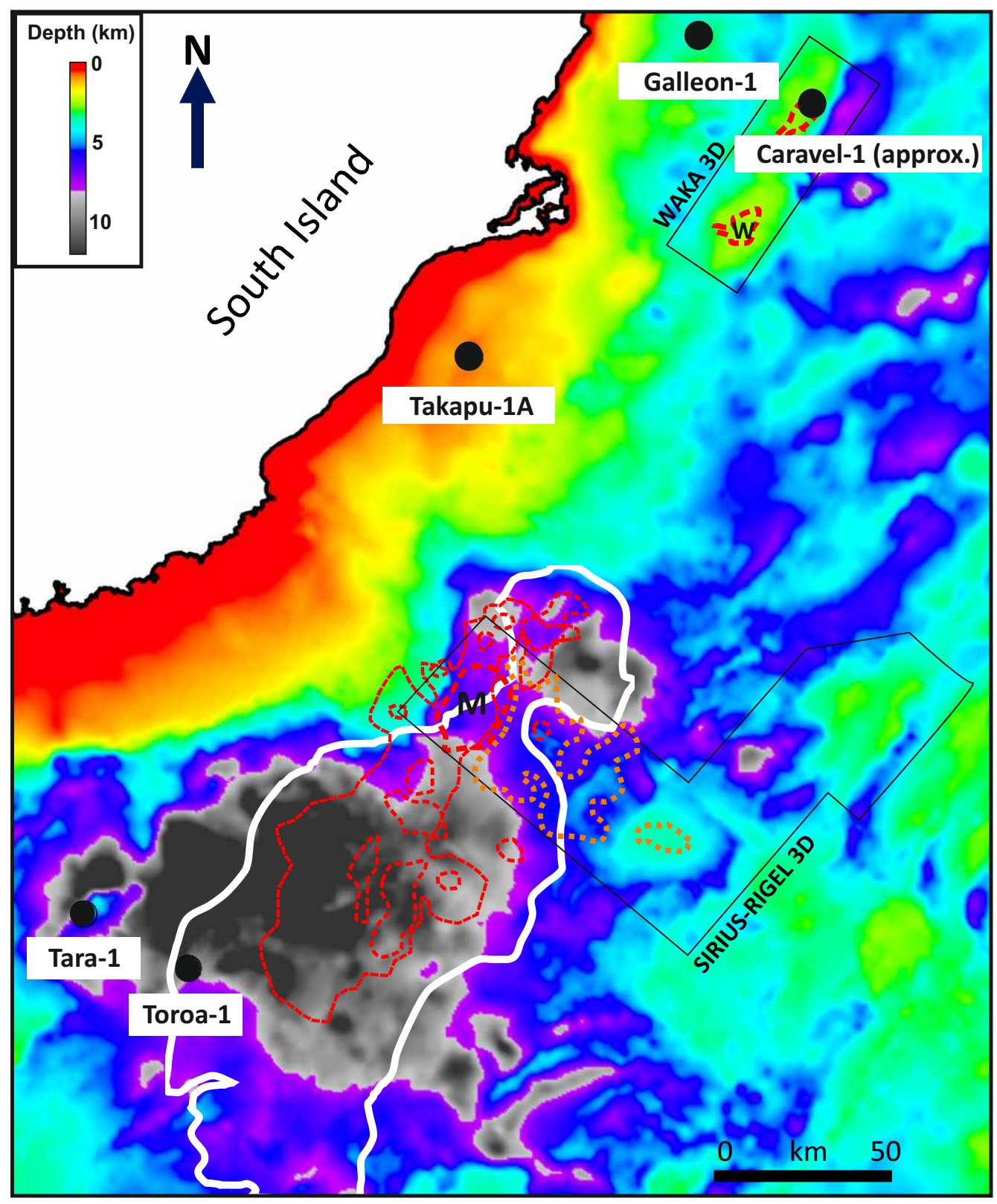

Figure 4 


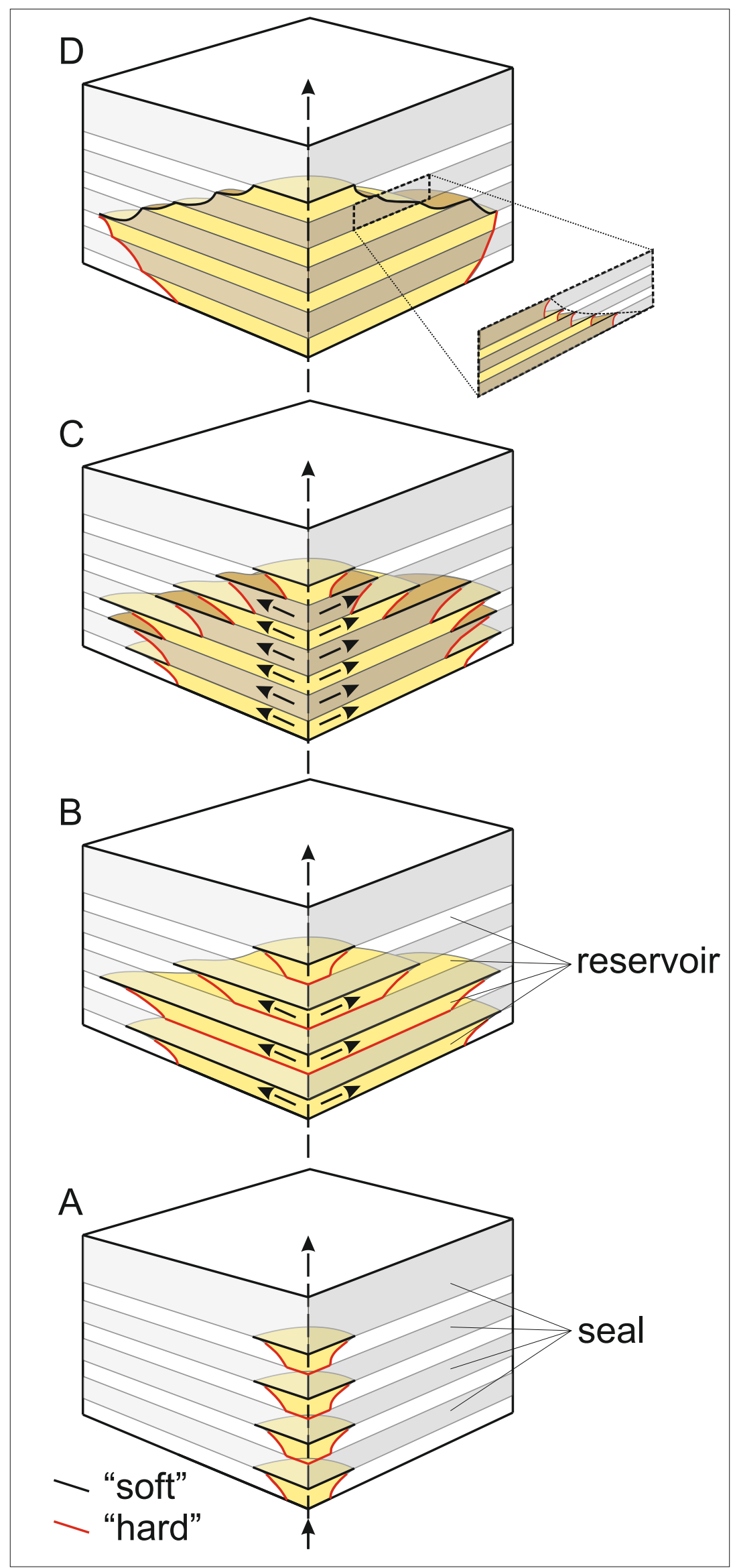

Figure 5 

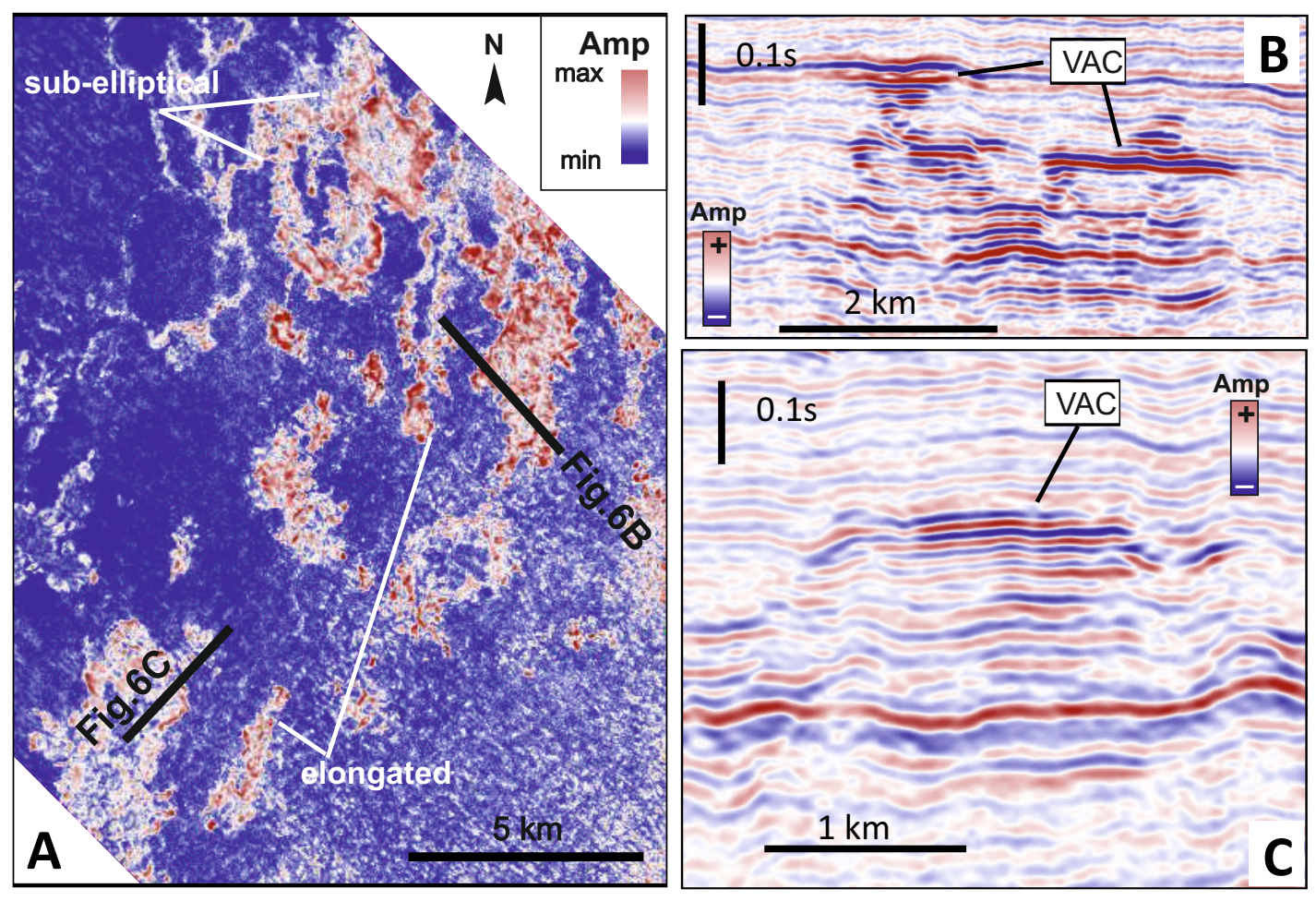

Figure 6 


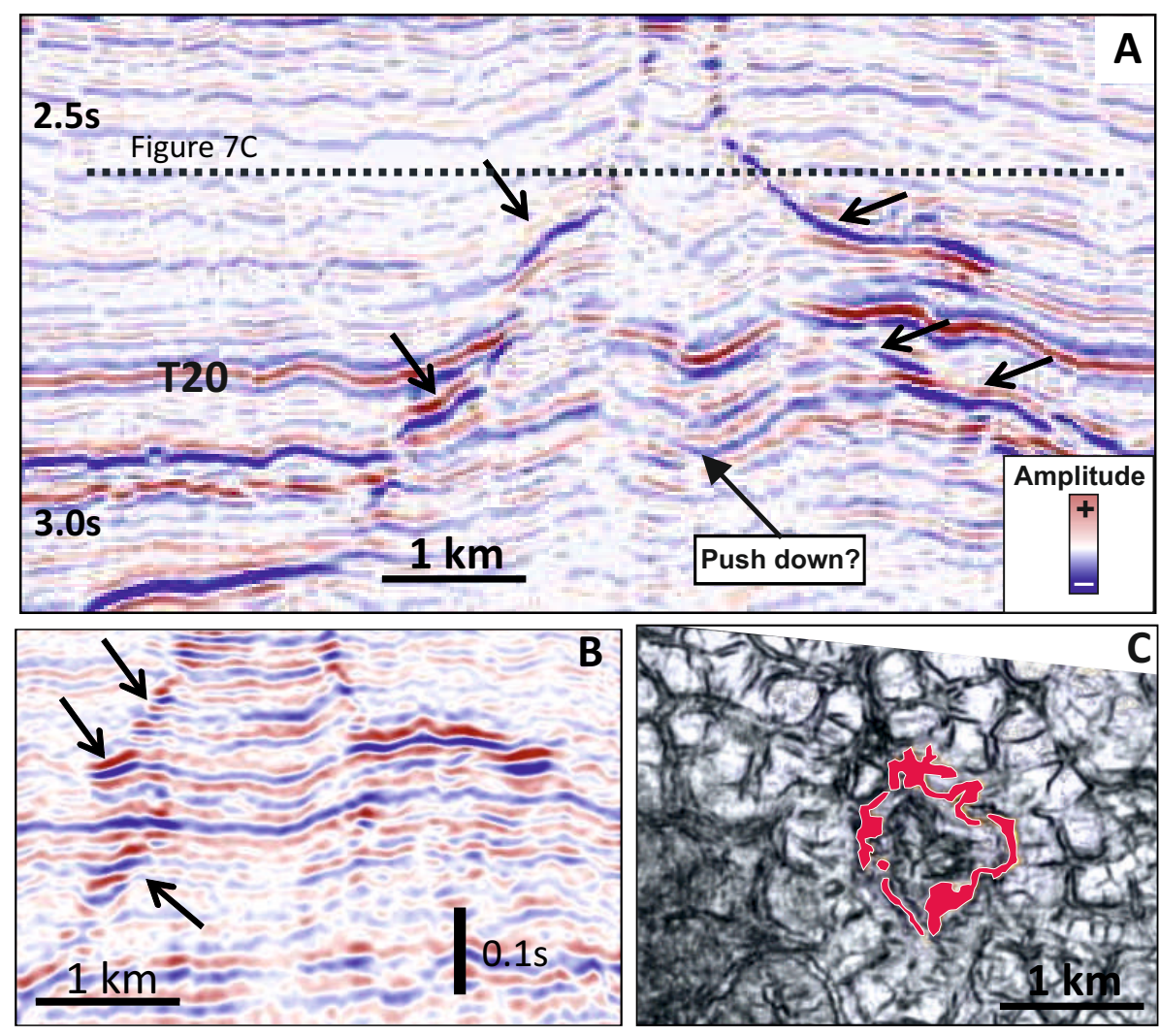

Figure 7 

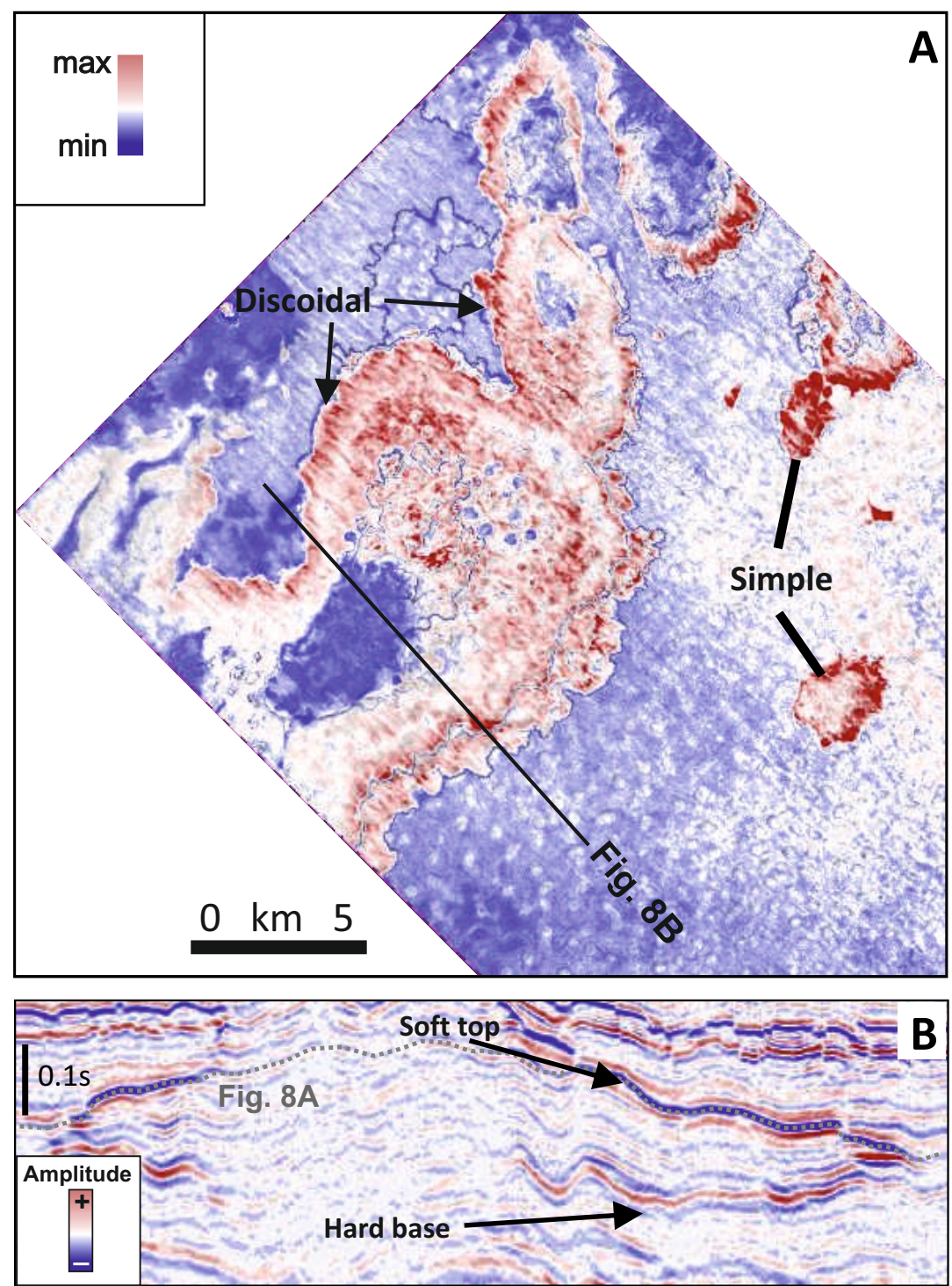

Figure 8 


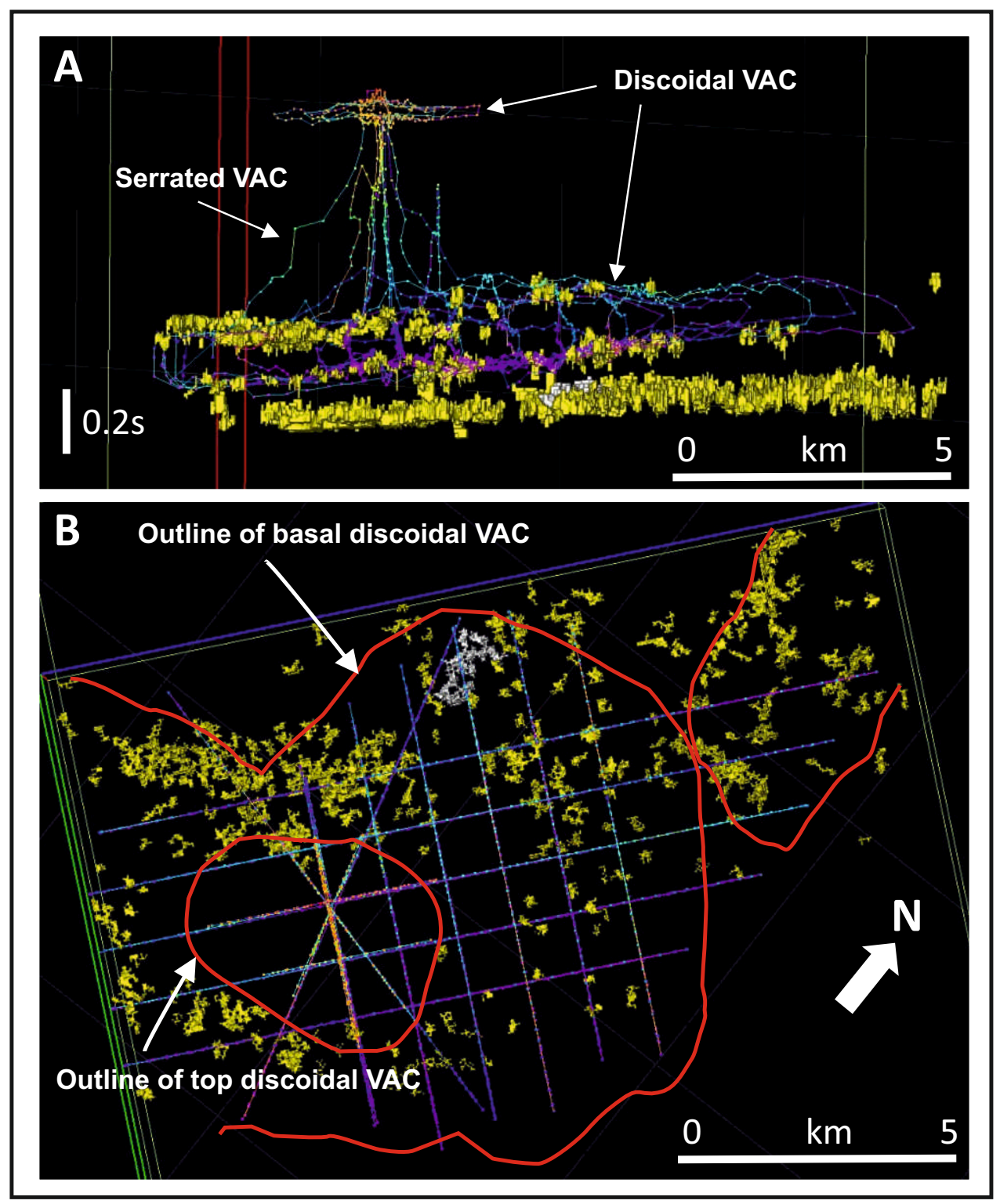

Figure 9 

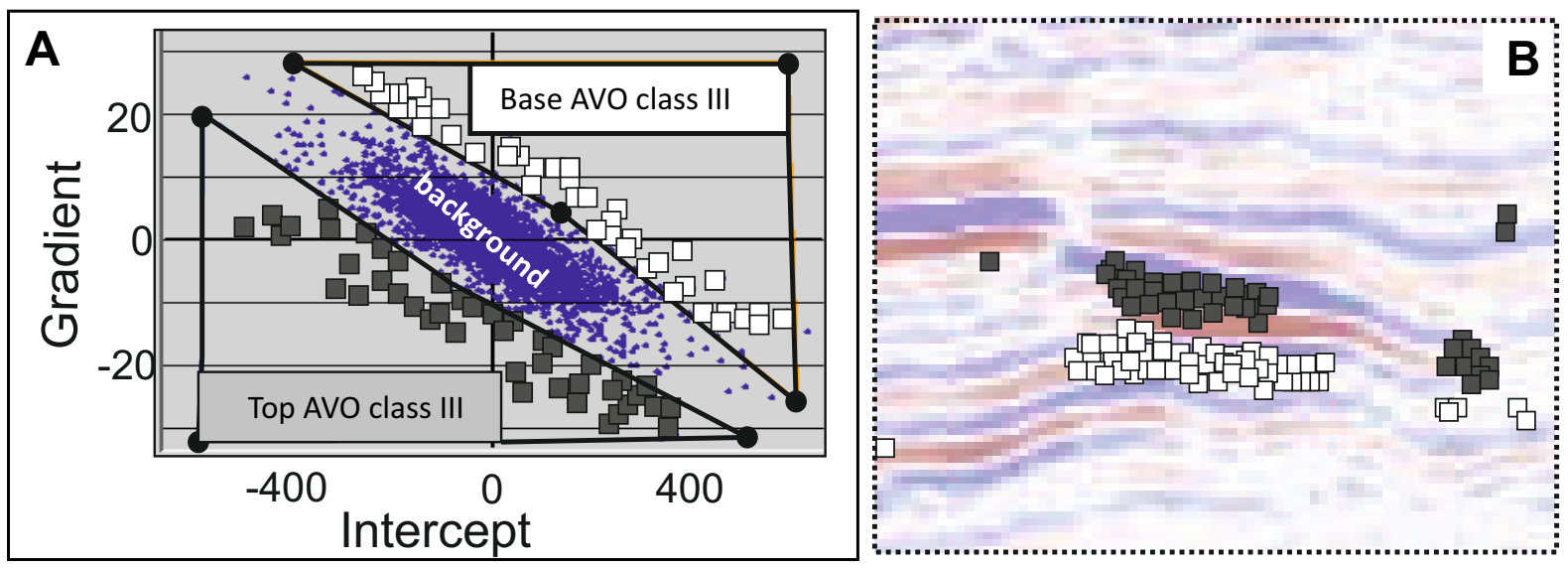

Figure 10 


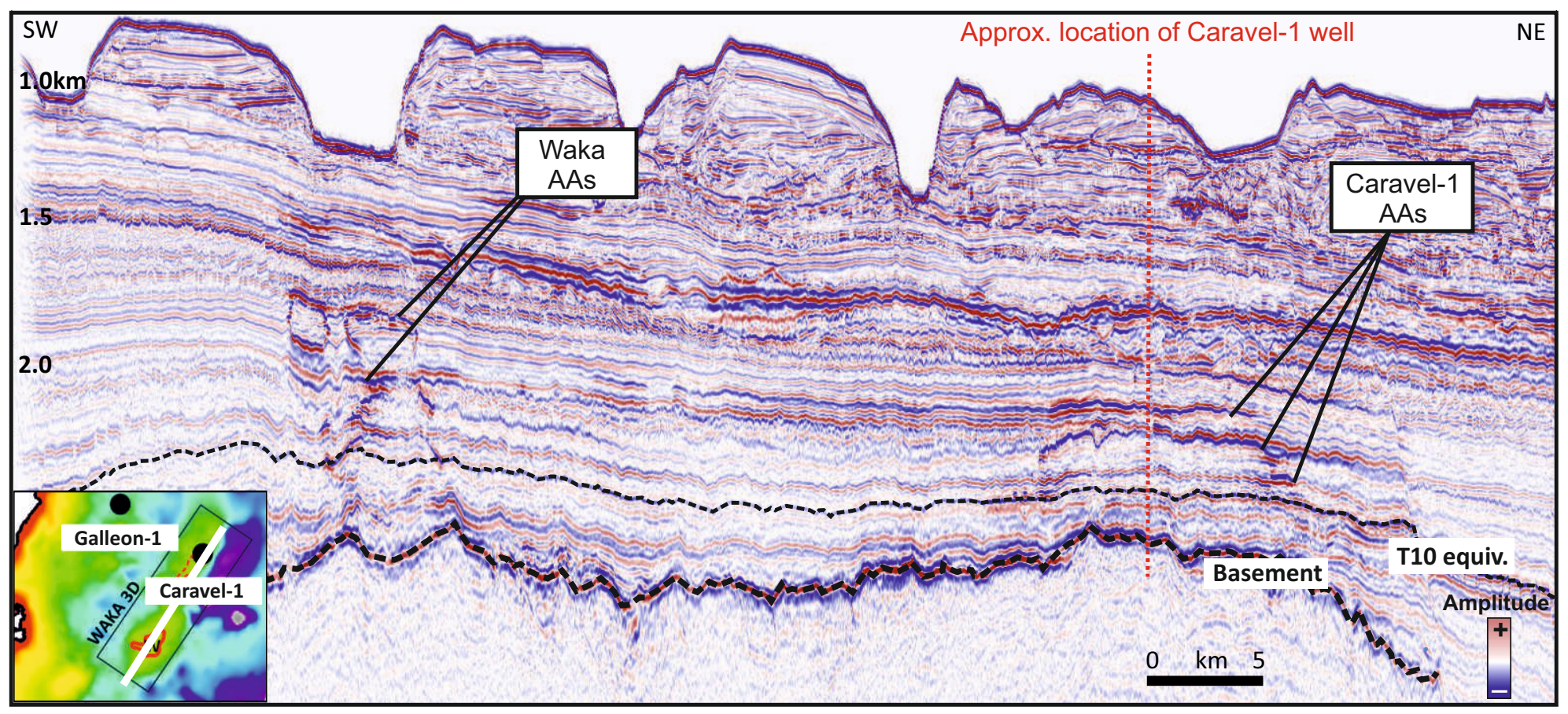

Figure 11 


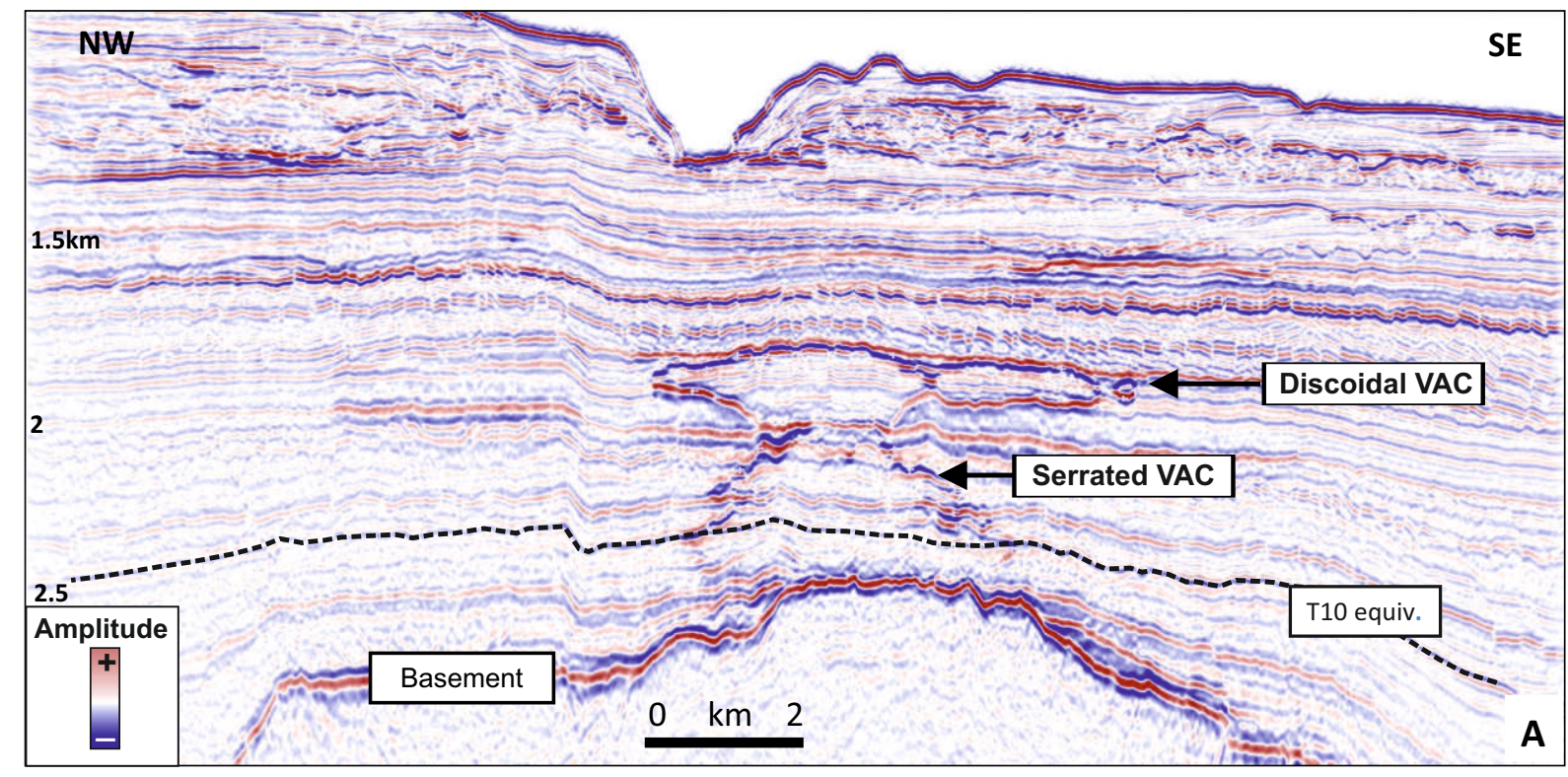

Figure 12
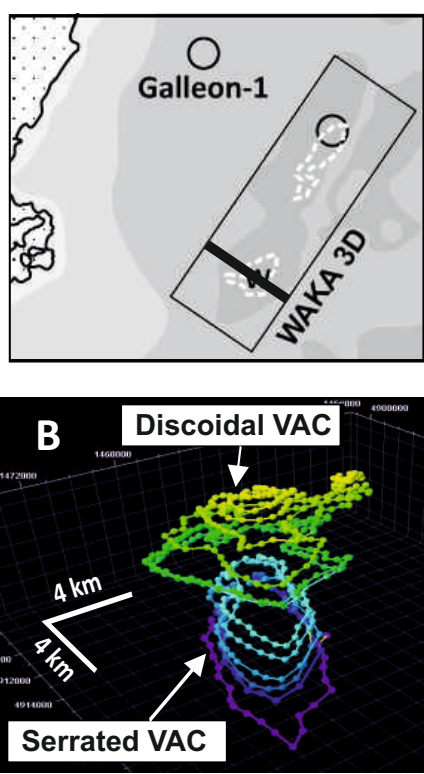

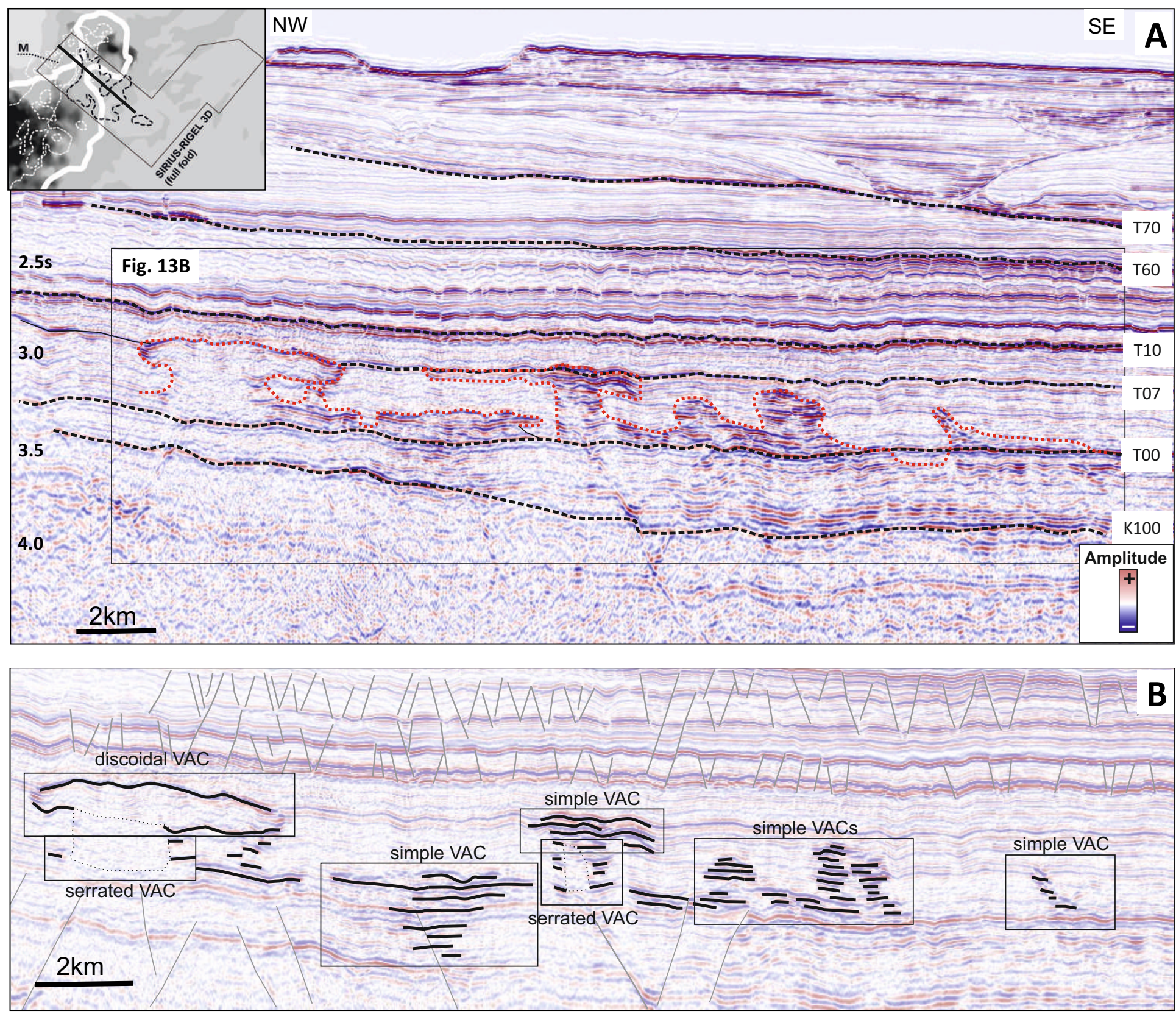

Figure 14 


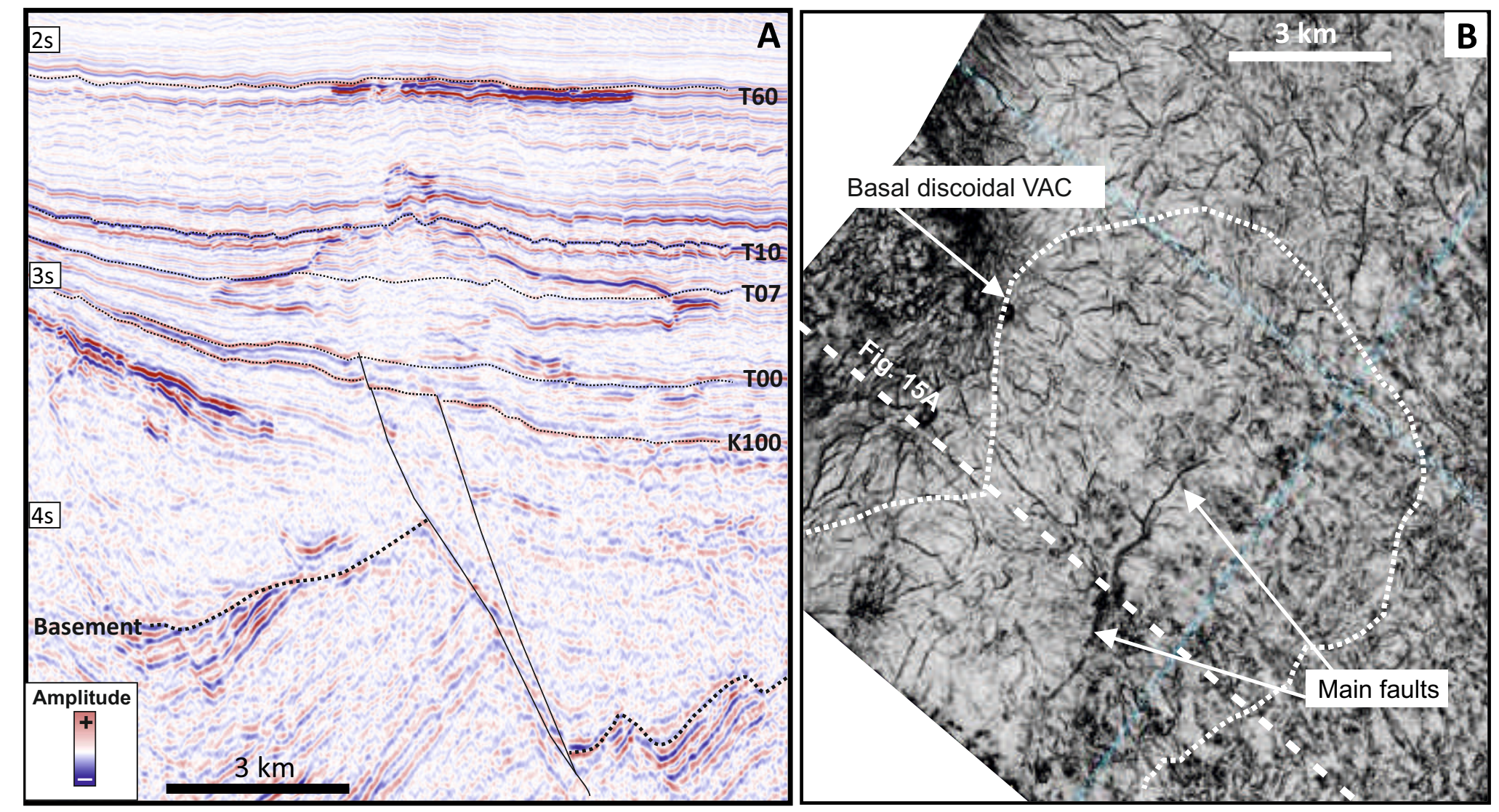

Figure 15 


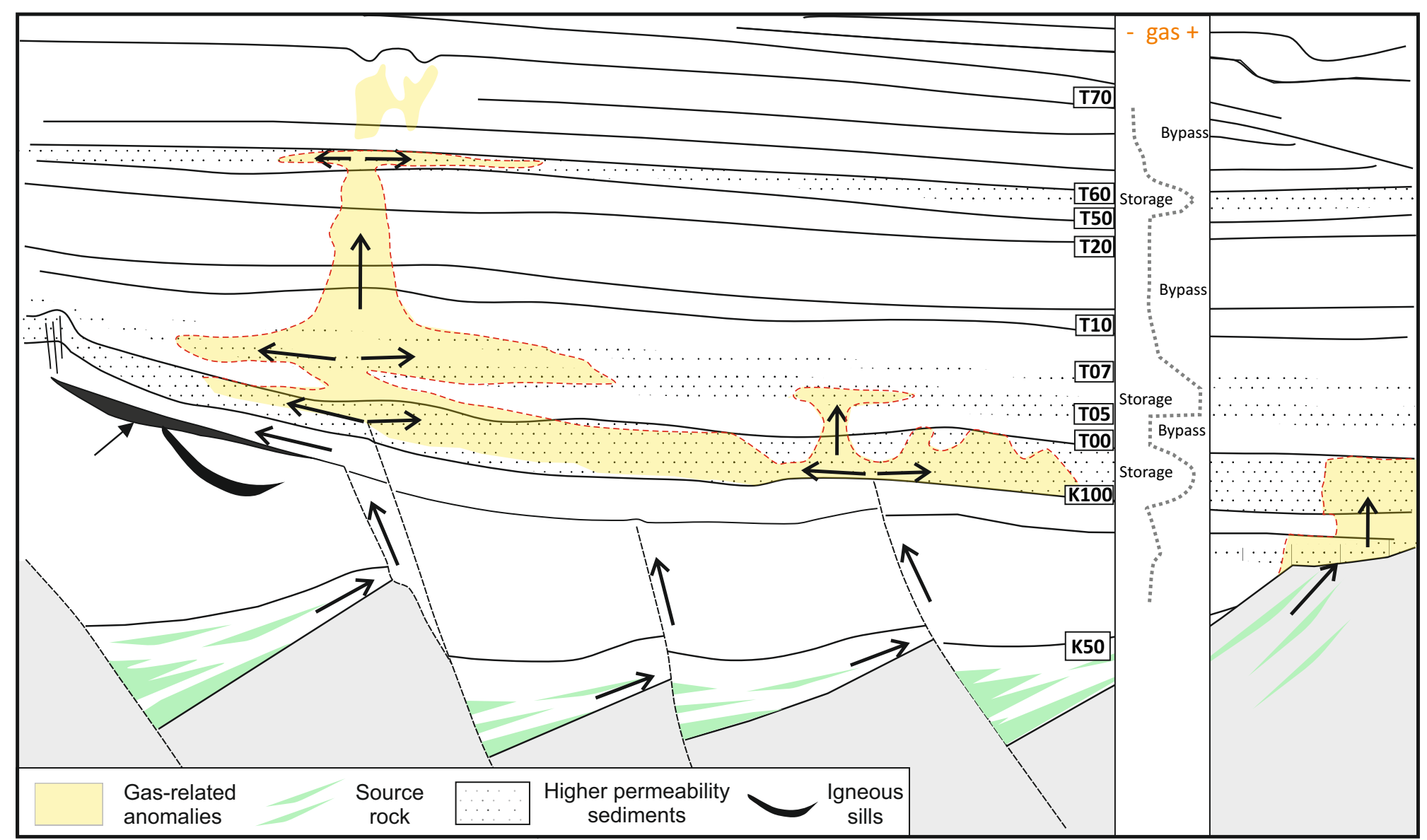

Figure 16 